\title{
Dendritic coincidence detection in Purkinje neurons of awake mice
}

\section{Authors: Christopher J. Roome ${ }^{1 *}$, Bernd Kuhn ${ }^{1 *}$}

Affiliation: ${ }^{1}$ Optical Neuroimaging Unit, Okinawa Institute of Science and Technology Graduate University (OIST), 1919-1 Tancha, Onna-son, Okinawa, 904-0495, Japan.

$$
\text { *chris.roome@oist.jp, bkuhn@oist.jp }
$$

\section{Summary:}

Dendritic coincidence detection is thought fundamental to neuronal processing, yet the underlying dendritic voltage-calcium relationship remains unexplored in awake animals. Here, using simultaneous voltage and calcium two-photon imaging of Purkinje neuron spiny dendrites, we show how coincident sub- and suprathreshold synaptic inputs modulate dendritic calcium signaling during sensory stimulation in awake mice. Sensory stimulation evokes subthreshold excitatory and inhibitory post-synaptic potentials, that coincide with suprathreshold dendritic spikes triggered by climbing fiber and parallel fiber synaptic input. Purkinje neuron dendrites integrate these inputs in a time-dependent and non-linear fashion to enhance the sensory evoked dendritic calcium signal. Intrinsic supra-linear dendritic mechanisms, including voltage gated calcium channels and metabotropic glutamate receptors, are recruited cooperatively to expand the dynamic range of sensory evoked dendritic calcium signals. This establishes how dendrites use multiple interplaying mechanisms to perform coincidence detection, as a fundamental and ongoing feature of dendritic integration during behavior.

\section{Keywords:}

Dendritic integration, coincidence detection, Purkinje neuron, cerebellum, awake, subthreshold, dendritic complex spike, dendritic spike voltage imaging, two-photon microscopy 
Introduction:

Dendritic integration is fundamental to signal processing in the brain. So far, most studies on dendritic integration were performed in vitro, in the absence of physiological inputs (Larkum et al., 2009; Markram et al., 1997; Stuart and Häusser, 2001; Wang et al., 2000). As such, our understanding of the basic components of dendritic integration; the frequency, amplitude, and spatio-temporal distribution of synaptic inputs under physiological conditions, and how these inputs are integrated by dendrites in awake behaving animals, remains incomplete.

Coincidence detection is a basic form of dendritic integration. By detecting coincident synaptic input, it is thought that neurons distinguish important signals from ongoing synaptic activity and modify synaptic strength through synaptic plasticity (Brown et al., 1990).

Purkinje neuron (PN) dendrites in the cerebellum are ideally suited to perform coincidence detection. They receive excitatory synaptic input from two distinct pathways; the climbing fiber (CF) and numerous parallel fibers (PF). CFs project from the inferior olive and evoke suprathreshold dendritic calcium spikes. PFs relay mossy fiber activity originating from the lateral reticular nucleus and pontine nuclei and together with synaptic input from inhibitory molecular layer interneurons (MLIs), evoke subthreshold postsynaptic potentials in the PN dendrites (Konnerth et al., 1990; Roome and Kuhn, 2018). In cerebellar slices, paired stimulation of these sub- and suprathreshold inputs evoke 'supra-linear' dendritic calcium signals in PNs, whereby the signal amplitude is larger than the sum of calcium signals triggered by PF and CF input alone. At PF-PN synapses supra-linear calcium signals lead to a form of synaptic plasticity, known as long-term depression (LTD) (Miyata et al., 2000; Wang et al., 2000).

This particular coincident detection process is well studied in PN spines and dendrites in cerebellar slices, and supports early theoretical predictions for motor learning in the cerebellum (Marr, 1969), but remains a controversial component in the theory of cerebellar function and motor learning (Mauk et al., 1998; Najafi and Medina, 2013; Sakurai, 1987; Schonewille et al., 2011; Wang et al., 2000). A corresponding detailed description of dendritic coincidence detection from awake animals is still missing, and the behavioral conditions under which these processes occur are unknown. Critically, coincidence detection 
64 of PF and CF input has not been confirmed in vivo, and recent studies have failed to detect 65 supra-linear dendritic calcium signals triggered by coincident PF and CF input (Gaffield et 66 al., 2019; Gaffield et al., 2018).

67

68

Due to technical limitations, PF evoked input to PN dendrites - that are predominantly 69 subthreshold voltage signals - have been thus far undetectable in vivo. As such, confirming 70 physiological interaction between $\mathrm{PF}$ and $\mathrm{CF}$ input has not been possible, and previous in 71 vivo studies have instead focused on coincident MLI and CF activity and suprathreshold calcium signals only (Callaway et al., 1995; Gaffield et al., 2018; Kitamura and Häusser, 73 2011). We recently developed a technique to record both sub- and suprathreshold dendritic 74 voltage signals, evoked by synaptic input in awake mice (Roome and Kuhn, 2018). Here by 75 combining simultaneous voltage and calcium imaging from the PN spiny dendrites, we 76 investigate sensory evoked dendritic signal processing and coincidence detection in PN 77 dendrites awake mice. 


\section{Results:}

Single PNs in lobule $\mathrm{V}$ of the cerebellar vermis were double labelled with voltage sensitive dye ANNINE-6plus and genetically encoded calcium indicator GCaMP6f, as

82 described previously (Roome and Kuhn, 2018) (see Supplementary Information). Briefly, a 83 chronic cranial window with access port (Roome and Kuhn, 2014) permitted two photon 84 imaging, single neuron labelling and drug delivery (Figure 1a-c). In total 54 PNs in 23 mice were labelled and several PNs (up to 5) were labeled and recorded from in the same mouse (Figure $1 \mathrm{~b})$. Two photon linescan imaging $(2 \mathrm{kHz})$ recorded dendritic voltage and calcium signals simultaneously from the spiny PN dendrites, predominantly comprising PF-PN synapses, at a depth of $30-70 \mu \mathrm{m}$ below the dura (Figure 1c). Simultaneous voltage and

89 calcium recordings were spatially averaged (across many dendritic processes) to maximize 90 the signal to noise ratio, at a temporal resolution of $0.5 \mathrm{~ms} / \mathrm{line}$. As the voltage response of 91 ANNINE-6plus is linear down to a nanosecond time scale, the averaged voltage imaging signal represents the average membrane potential of dendritic shafts and dendritic spines

93 within the point spread function of excitation along the scan line. 
bioRxiv preprint doi: https://doi.org/10.1101/2020.06.15.152496; this version posted June 15, 2020. The copyright holder for this preprint (which was not certified by peer review) is the author/funder, who has granted bioRxiv a license to display the preprint in perpetuity. It is made available under aCC-BY 4.0 International license.
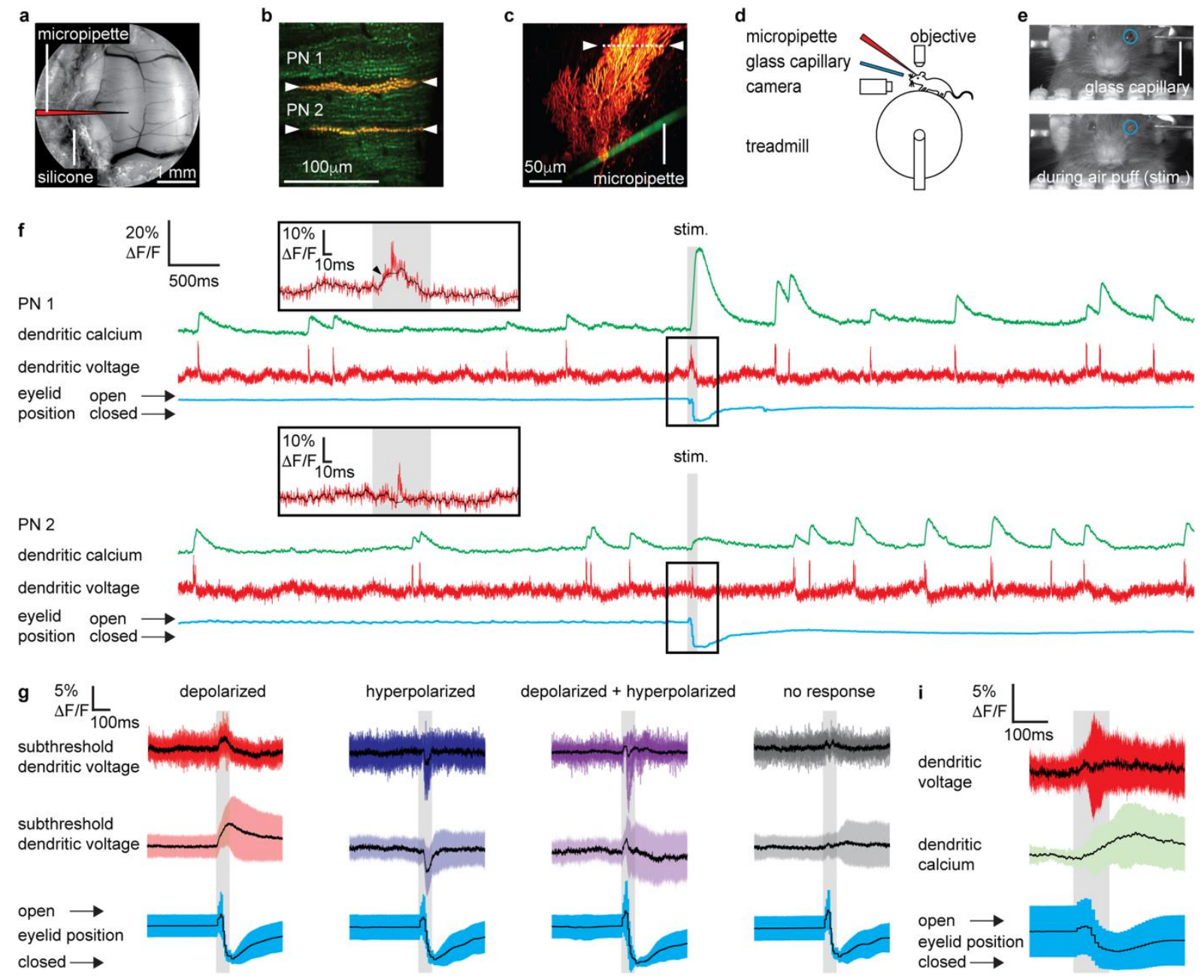

n

97 Figure 1. Coincident parallel fiber and climbing fiber synaptic input to Purkinje neuron dendrites during sensory evoked responses. (a) A chronic cranial window with access port on the cerebellar vermis lobule $\mathrm{V}$ was used for imaging from the dendrites of single PNs and allowed access to the brain via micropipette (schematically indicated). (b) 2P image of the spiny dendrites of two PNs (PN1 and PN2) labelled with voltage sensitive dye ANNINE-6plus (red) and genetically encoded calcium indicator GCaMP6f (green), resulting in double labelling (yellow). (c) Reconstruction of a single labelled PN showing position of 2P linescan (white dashed line and arrows) and the micropipette (green) positioned in the granular layer (50 $\mu \mathrm{m}$ below the soma) used for pharmacological manipulation. (d) Sketch of the setup with a mouse mounted on a treadmill under a 2P microscope for imaging in lobule $\mathrm{V}$ of the cerebellar vermis. A glass capillary was used to deliver a $100 \mathrm{~ms}$ air puff directed towards the ipsilateral eye. (e) A camera was used to monitor mouse movements and record eye responses during the air puff. Blue circles show ROIs used to record eyelid movement. (f) Single trial 
recordings of simultaneous dendritic voltage (red traces) and calcium (green traces) from PN1 and PN2 shown in (c). Suprathreshold signals are clearly visible in both voltage and calcium traces. Blue traces show average intensity of ROI used to record eye responses. Grey bars show full duration of air puff stimulus. The calcium recording from PN1 shows a dramatically enhanced evoked calcium signal during the air puff while the calcium recording from PN2 does not. Insets show zoomed voltage traces during air puff stimulation. The voltage recording in PN1 inset shows depolarizing subthreshold voltage signal, during the air puff (small black arrow and black trace; $10 \mathrm{~ms}$ boxcar filtered voltage recording), while the voltage recording from PN2 shows no subthreshold signal. (g) Subthreshold voltage signals during air puff sorted into 'depolarized' (red), 'hyperpolarized' (blue), 'depolarized + hyperpolarized' (purple) and 'no response' (grey) groups, showing single recordings from a single PN (top traces; black trace shows mean) and averages all recordings in each group (middle traces; black trace shows mean, colored trace shows SD) and corresponding eyelid responses (bottom traces; black trace shows mean, colored trace shows SD). (h) Fraction of recordings resulting in each response type; depolarized ('dep.'), hyperpolarized ('hyp.'), depolarized + hyperpolarized ('dep. + hyp.') and 'no response' for individual PNs. PNs are grouped based on their most frequent response type; depolarized (red, 36/54 PNs); hyperpolarized (blue, 6/54 PNs); depolarized + hyperpolarized (purple, 1/54 PN); no response (grey, 11/54 PNs), bars show mean and SD for all PNs in each group. (i) Averages of subthreshold voltage (red) and calcium (green) dendritic signaling during sensory stimulation (only recordings with no dendritic spikelets and both depolarizing and hyperpolarizing signals are included) and corresponding eye responses (blue), black lines show mean, colored traces show SD. (j) Relationship between average subthreshold dendritic voltage and calcium during the stimulus, solid line is linear regression (Pearson's $r=0.71, p=4.51 \times 10^{-10}$ ) and dashed lines show $95 \%$ confidence intervals. head-fixed under a two-photon microscope (Figure 1d). Linescan recordings (10 seconds in length) included a 100ms sensory stimulus beginning 5 seconds after recording onset, giving an air puff directed at the ipsilateral eye. Air-puffs (pressure: 30psi) were delivered via a glass capillary positioned $2 \mathrm{~cm}$ from the eye to evoke a reliable eye blink reflex in the ipsilateral eye, which was monitored using a video camera (Figure 1e). This form of sensory stimulation was chosen to evoke dendritic calcium signals in PNs of lobule V, as described 138 previously (Najafi et al., 2014a). Mice were naïve to the sensory stimulus receiving $(<5)$ test 139 stimuli before recording began and 5-30 stimuli (average of 13 recordings per PN) during a 140 single recording session. During sessions all air puffs were unexpected, triggering an eye 141 blink reflex in the ipsilateral eye and no conditioned pre-stimulus eye blink responses were 142 observed, indicating that the mouse did not learn to expect the stimulus (Figure 1 - figure supplement 1). 
We previously described two types of suprathreshold dendritic signals in the PN

147 dendrites of awake mice; dendritic complex spikes 'DCS' triggered by CF input and single

148 dendritic spikes 'DS' triggered by strong PF input (Roome and Kuhn, 2018) (see Figure 1 -

149 figure supplement 2 and Methods for DCS and DS detection criteria). DCS comprise a burst

150 of rapid and distinct spikelets (typically 2-5 spikelets, each 1-2 ms in duration), associated

151 with a large dendritic calcium signal. DS are characterized by a gradually ramping membrane

152 potential, followed by a single spikelet and small associated calcium signal. We also

153 described dendritic voltage signals evoked by synaptic input that correlate with action

154 potential firing at the PN soma, but these did not trigger dendritic spikes and associated

155 calcium signals, and so we refer to these as 'subthreshold' dendritic signals (Roome and

156 Kuhn, 2018).

Sensory stimulation evokes sub- and suprathreshold signals in Purkinje neuron dendrites of awake mice

Simultaneous voltage and calcium dendritic recordings revealed both subthreshold and suprathreshold signaling during sensory stimulation (Figure 1f). Suprathreshold signals (DCS and DS) were often, but not always, detected during coincident subthreshold signals. For example (Figure 1f), two PNs, PN1 and PN2, in the same mouse show responses; PN1 shows a slow subthreshold depolarization (black trace) with a DCS riding on top (red trace), while PN2 inset shows only a DCS, with no detectable subthreshold signal. Occasionally we also detected only subthreshold signals during sensory stimulation, with no coincident suprathreshold signal (see below). The sub- and suprathreshold dendritic signals were not evoked during voluntary eye blinks or detected while the mouse was anaesthetized and presented with the same air-puff stimuli (Figure 1 - figure supplement 3 and 4, respectively).

Sensory evoked subthreshold dendritic signaling has not been explored in awake animals. Thus, we began by analyzing the subthreshold dendritic signals. The amplitude and direction (i.e. depolarizing or hyperpolarizing) of evoked subthreshold voltage signals was variable between individual PNs and on a trial by trial basis (Figure $1 \mathrm{~g}$-j and Figure 2a). By removing all suprathreshold signals (see Methods and Figure 1 - figure supplement 2 for spikelet detection and removal), we sorted voltage recordings based upon the amplitude and

178 direction of the sensory evoked subthreshold response (Figure 1g and Figure 1 - figure 
supplement 2). Approximately 52\% of voltage recordings displayed a depolarizing subthreshold signal (with detection threshold > 2 standard deviations above baseline), and $25 \%$ showed no response during the stimulus $(\mathrm{n}=696)$. The remaining $14 \%$ showed hyperpolarizing voltage signals (detection threshold $>2$ standard deviations below baseline) and $7 \%$ had a truncated signal that appeared to be a superposition of both depolarizing and hyperpolarizing signals (detection threshold > 2 standard deviations above and below baseline at different time points during the stimulus).

Individual PNs displayed a trend towards a particular subthreshold voltage response (Figure 1h). The majority of PNs exhibited 'depolarizing' responses (36/54 PNs), and the remaining PNs exhibited either 'hyperpolarizing' (6/54 PNs), 'no response' (11/54 PNs), or both 'depolarizing + hyperpolarizing' (1/54 PNs). The average fraction of recordings across all PNs showing their preferred response was $0.65 \pm 0.18$ (mean $\pm \mathrm{SD}, \mathrm{n}=54 \mathrm{PNs}$ ). Combining voltage recordings from all groups, we found that the average amplitude of all sensory evoked subthreshold voltage signals was positive relative to baseline (i.e. depolarizing); $\left(2.91 \pm 4.3 \% \Delta \mathrm{F} / \mathrm{F}\right.$, mean $\pm \mathrm{SD}, 54 \mathrm{PNs}$, t-test, $\left.\mathrm{p}=7.25 \times 10^{-6}\right)$, (Figure $1-$ figure supplement 5). Therefore, on average, the sensory evoked subthreshold voltage signal is excitatory, and so elicited by PF synaptic input.

While dendritic calcium signals in PNs are predominantly suprathreshold and mediated by P/Q-type voltage gated calcium channels (VGCCs) (Usowicz et al., 1992), additional mechanisms also contribute to dendritic calcium signaling at PF-PN synapses, that do not require suprathreshold dendritic spikes. For example, glutamate released during PF input can activate group 1 metabotropic glutamate receptors (mGluR1), which are also expressed at PF-PN synapses, triggering calcium influx (Tempia et al., 2001) and modulating low threshold T-type VGCCs (Ait Ouares and Canepari, 2020; Hildebrand et al., 2009; Otsu et al., 2014). Whether or not these signals are involved in dendritic signaling during sensory stimulation has not been confirmed.

To determine if subthreshold dendritic calcium signals are evoked by sensory stimulation, we selected all recordings in which no suprathreshold (DCS or DS) signals were detected (i.e. no suprathreshold dendritic spikes and calcium signals) in a window $\pm 300 \mathrm{~ms}$ of

211 the stimulus onset. Averaging these recordings revealed a gradual increase in dendritic 
212 calcium during sensory stimulation (dendritic calcium at stimulus offset relative to baseline:

$2131.8 \pm 2.8 \% \Delta \mathrm{F} / \mathrm{F}$, mean $\pm \mathrm{SD}, \mathrm{n}=59$, t-test, $\mathrm{p}=5.9 \times 10^{-6}$ ) (Figure 1i). Calculating the average

214 subthreshold voltage and calcium signal over the full sensory stimulus, on a trial by trial

215 basis, revealed a subthreshold voltage-calcium relationship $(\mathrm{n}=59$, Pearson's $\mathrm{r}=0.71, \mathrm{p}=$ $2164.51 \times 10^{-10}$ ) (Figure $1 \mathrm{j}$ ).

218 Single trial recordings of simultaneous dendritic voltage (red traces) and calcium

219 (green traces), during sensory stimulation (stim.) for each subthreshold voltage response type;

220 'depolarizing', 'hyperpolarizing', 'depolarizing + hyperpolarizing' and 'no response', are

221 shown in Figure 2a. The temporal profile of each voltage response was resolved by sorting

222 and averaging voltage signals in each response group (Figure 2b). Depolarizing signals

223 increased gradually throughout the stimulus, beginning $9 \pm 3$ ms (mean $\pm S D, n=307$ ) after

224 stimulus onset, and reaching a maximum after $101 \pm 3 \mathrm{~ms}$. Hyperpolarizing signals were

225 sharper, and their onset occurred later, beginning $35 \pm 2 \mathrm{~ms}$ (mean $\pm \mathrm{SD}, \mathrm{n}=83$ ) after

226 stimulus onset, and reaching a minimum $57 \pm 2 \mathrm{~ms}$ (mean \pm SD) after stimulus onset. 
bioRxiv preprint doi: https://doi.org/10.1101/2020.06.15.152496; this version posted June 15, 2020. The copyright holder for this preprint (which was not certified by peer review) is the author/funder, who has granted bioRxiv a license to display the preprint in perpetuity. It is made available under aCC-BY 4.0 International license.

a $20 \%$

$\Delta \mathrm{F} / \mathrm{F} \underset{500 \mathrm{~ms}}{ }$ depolarized

dendritic calcium

dendritic voltage

eyelid position

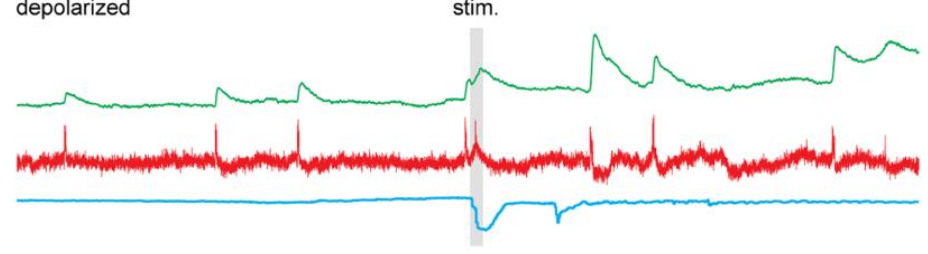

hyperpolarized

dendritic calcium

dendritic voltage

eyelid position

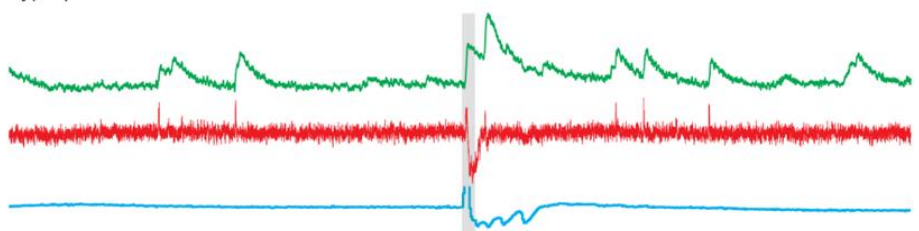

depolarized + hyperpolarized

dendritic calcium

dendritic voltage

eyelid position

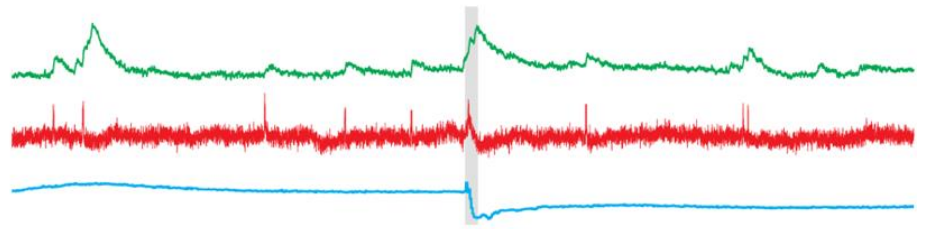

no response

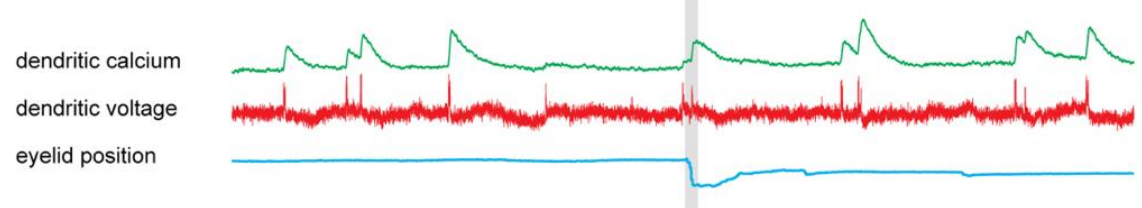

b

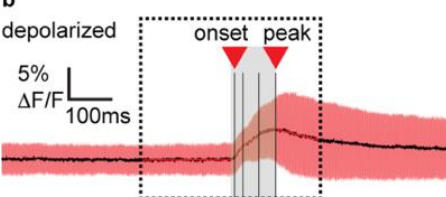

hyperpolarized
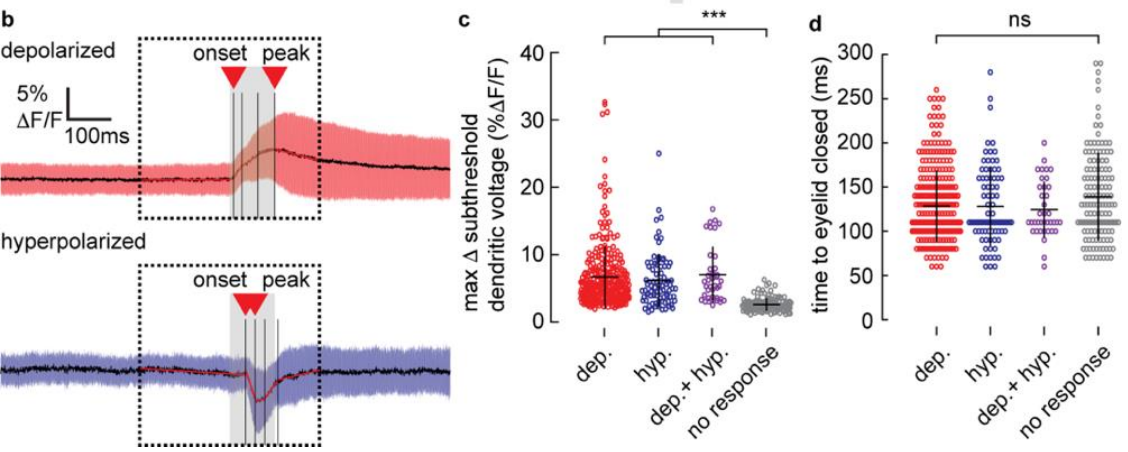

230 Figure 2. Stimulus evoked subthreshold dendritic voltage signals and their relationships with eyelid closure time. (a) Single trial recordings of simultaneous dendritic voltage (red traces) and calcium (green traces) during sensory stimulation (stim.). Suprathreshold signals are clearly visible in both voltage and calcium traces. Blue traces show average intensity of ROI used to record eyelid position (eyeblink responses). Grey bars show full duration of air puff stimulus. Each example shows subthreshold voltage signals during stimulus belonging to each response type; depolarized, hyperpolarized, depolarized + hyperpolarized or no response (top to bottom respectively). Recordings were sorted based on the subthreshold response during the stimulus, by first removing spikelets from the voltage recording, binning in $10 \mathrm{~ms}$ epochs, and thresholding at \pm 2 standard deviations. (b) Estimates for onset time and peak (shown by red triangles) in depolarizing (top) and hyperpolarizing (bottom) signals were calculated by minimizing the sum of residual (squared) error within four regions of the signal (shown by black bars) and fitting a linear regression within each region (red lines). (c) Maximum change in subthreshold voltage measured during the stimulus for all recordings in each response group. (d) Time for eyelid 
to close after stimulus onset for each response group. Horizontal and vertical bars show mean \pm SD respectively.

We calculated the maximum change in subthreshold voltage during the sensory stimulus (excluding dendritic spikes), for all recordings in each response group (Figure 2c). The maximum change in subthreshold voltage was similar between depolarizing $(6.7 \pm 4.7$ $\% \Delta \mathrm{F} / \mathrm{F}$, mean $\pm \mathrm{SD}, \mathrm{n}=307)$, hyperpolarizing $(6.1 \pm 4.0 \% \Delta \mathrm{F} / \mathrm{F}$, mean $\pm \mathrm{SD}, \mathrm{n}=83)$ and depolarizing + hyperpolarizing groups $(7.0 \pm 4.2 \% \Delta \mathrm{F} / \mathrm{F}$, mean $\pm \mathrm{SD}, \mathrm{n}=38)$ and significantly larger than the no response group $(2.6 \pm 1.0 \% \Delta \mathrm{F} / \mathrm{F}$, mean $\pm \mathrm{SD}, \mathrm{n}=133)$, ANOVA, $\mathrm{p}<1.2 \times 10^{-8}, \mathrm{n}=561,49$ PNs. The time of eyelid closure (measured from stimulus onset to maximum eyelid closure) was independent of response type (Figure 2d); depolarized $(128 \pm 40 \mathrm{~ms}$, mean $\pm \mathrm{SD})$, hyperpolarized $(123 \pm 44 \mathrm{~ms}$, mean $\pm \mathrm{SD})$, depolarized + hyperpolarized $(124 \pm 32 \mathrm{~ms}$, mean $\pm \mathrm{SD})$ and no response $(139 \pm 50 \mathrm{~ms}$, mean $\pm \mathrm{SD})$ groups, Kruskal-Wallis ANOVA, $\mathrm{p}>0.35, \mathrm{n}=561,49$ PNs. This confirmed that a lack of subthreshold response was not due to a failure of the sensory stimulus.

We used pharmacology to investigate the origin of the stimulus evoked dendritic signals. All sub- and suprathreshold signals were blocked by AMPA receptor antagonist CNQX $(100 \mu \mathrm{M})$ (and also by $\mathrm{Na}^{+}$channel blocker Lidocaine $(0.2 \%)$, Figure 3 - figure supplement 1). Single trial recordings of simultaneous dendritic voltage and calcium signaling during sensory stimulation under control and CNQX conditions from the same PN are shown in Figure 3a. Average eyelid responses under control $(n=45)$ and CNQX $(n=37)$ conditions from 5 PNs are shown in Figure $3 \mathrm{~b}$. The eyelid closure time following CNQX application was not significantly different to control conditions (Figure 3c); control (134 \pm 40 $\mathrm{ms}$, mean $\pm \mathrm{SD})$; CNQX $(156 \pm 44 \mathrm{~ms}$, mean $\pm \mathrm{SD})$, Kolmogorov-Smirnov, $\mathrm{p}=0.12, \mathrm{n}=82$, 5 PNs.

The maximum change in subthreshold voltage (measured within a $200 \mathrm{~ms}$ window after stimulus onset), was significantly reduced under CNQX conditions; control $(8.0 \pm 7.3 \%$ $\Delta \mathrm{F} / \mathrm{F}$, mean $\pm \mathrm{SD}, \mathrm{n}=45)$, and $\mathrm{CNQX}(4.4 \pm 3.4 \% \Delta \mathrm{F} / \mathrm{F}$, mean $\pm \mathrm{SD}, \mathrm{n}=46)$, unpaired $\mathrm{t}-$ test, $\mathrm{p}=0.003, \mathrm{n}=91,5$ PNs (Figure 3d). Accordingly, the voltage dependent subthreshold

273 calcium signal we detect during sensory stimulus (described in Figure 1i-j), was also blocked 274 by CNQX (Figure 3e) and also by Lidocaine (Figure 3 - figure supplement 1g); average 
bioRxiv preprint doi: https://doi org/10.1101/2020.06.15.152496; this version posted June 15, 2020. The copyright holder for this preprint (which was not certified by peer review) is the author/funder, who has granted bioRxiv a license to display the preprint in perpetuity. It is made available under aCC-BY 4.0 International license.

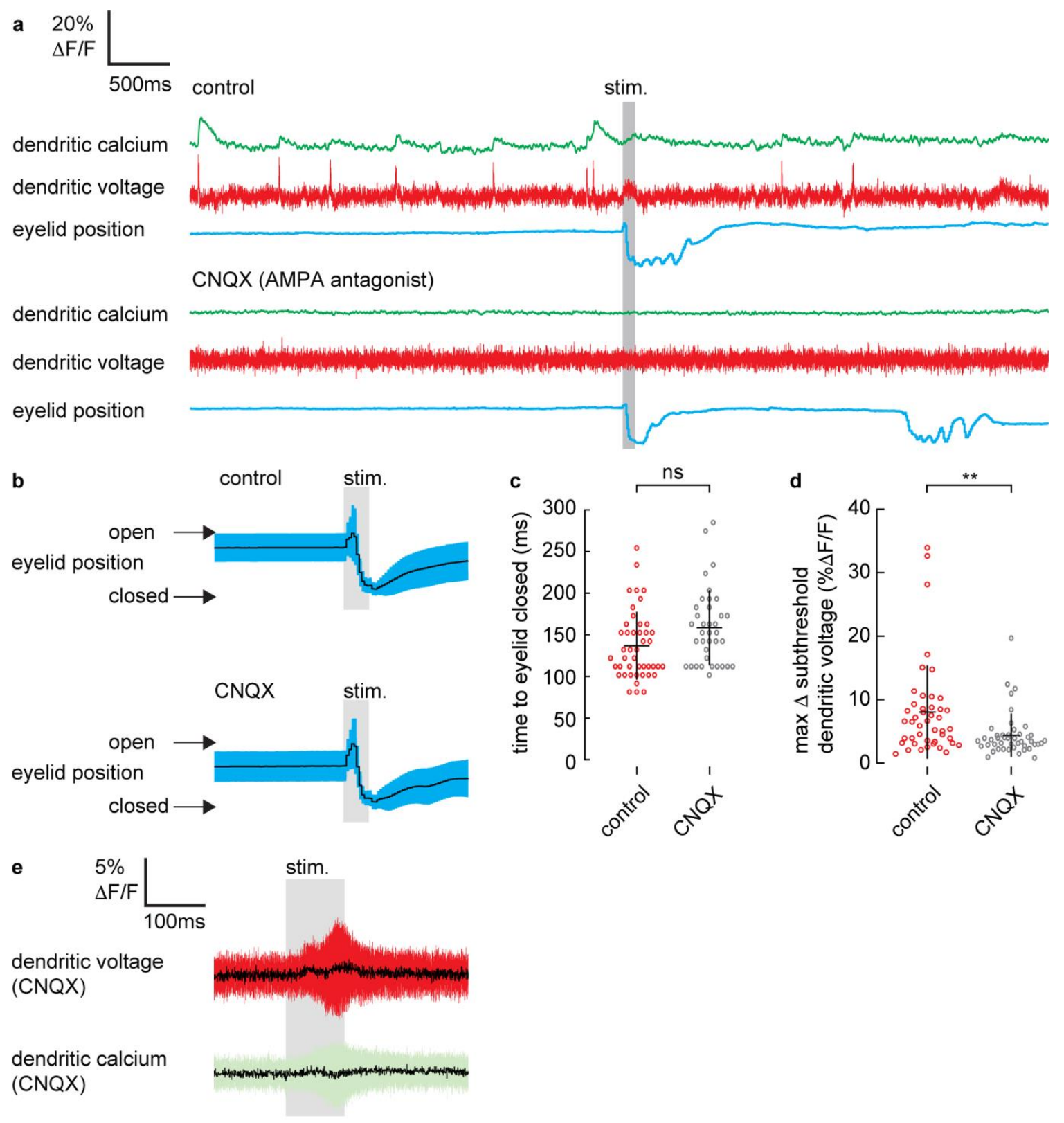

Figure 3. AMPA receptor antagonist, CNQX, blocks stimulus evoked subthreshold dendritic voltage and calcium signaling. (a) Single trial recordings of simultaneous dendritic voltage (red traces) and calcium (green traces) during sensory stimulation (stim.). Blue traces show average intensity of ROI used to record eyelid position (eyeblink responses). Grey bars show full duration of air puff stimulus. Top example shows voltage and calcium recordings during control conditions. Note in this example sensory stimulation evoked only a subthreshold voltage signal and no suprathreshold (calcium) signals during the stimulus. Bottom example shows recordings following CNQX application from the same PN. (b) Mean eye responses from control (top; $n=45$ ) and CNQX (bottom; $\mathrm{n}=37$ ) recordings (black trace shows mean; blue trace shows $\mathrm{SD}$ ). (c) Time for eyelid to close after stimulus onset under control (red) and CNQX (grey) conditions. (d) Maximum change in 
subthreshold voltage measured within a $200 \mathrm{~ms}$ window after stimulus onset under control and CNQX conditions. (e) Averages of subthreshold voltage (red) and calcium (green) dendritic signaling during sensory stimulation, following CNQX application, black line shows mean, colored trace shows SD. ** $\mathrm{p}<0.01$.

Metabotropic $\gamma$-aminobutyric acid type $\mathrm{B}\left(\mathrm{GABA}_{\mathrm{B}}\right)$ receptors are expressed at PF-PN synapses (Kulik et al., 2002), and so likely to contribute to inhibitory synaptic input at our recording location of the PN spiny dendrites. We assessed their contribution by applying $\mathrm{GABA}_{\mathrm{B}}$ receptor antagonist, CGP $35348(100 \mu \mathrm{M})$. Single trial recordings of simultaneous dendritic voltage and calcium signaling during sensory stimulation under control and CGP conditions from the same PN are shown in Figure 4a. Average eyelid responses under control $(\mathrm{n}=50)$ and CGP $(\mathrm{n}=59)$ conditions from 5 PNs are shown in Figure 4b. Application of CGP reduced sensory evoked hyperpolarizing voltage signals, but not the depolarizing voltage signals. Average subthreshold voltage (with spikelets removed) under control ( $\mathrm{n}=$ 50) and CGP $(n=59)$ conditions are shown in Figure $4 \mathrm{c}$. Note that $\mathrm{GABA}_{\mathrm{B}}$ blockade revealed a sustained sensory evoked depolarizing voltage signal, that continued after the stimulus had ended. The eyelid closure time following CGP application was not significantly different to control conditions (Figure 4d); control (114 $\pm 23 \mathrm{~ms}$, mean $\pm \mathrm{SD}, \mathrm{n}=50$ ); CGP $(125 \pm 34$ ms, mean \pm SD, $n=59)$, Kolmogorov-Smirnov, $\mathrm{p}=0.29, \mathrm{n}=109,5$ PNs. The onset, under control and CGP conditions is shown in Figure 4e. Stimulus evoked subthreshold voltage signals were significantly more positive (depolarizing) following CGP application; control $(-0.4 \pm 6.0 \% \Delta \mathrm{F} / \mathrm{F}$, mean $\pm \mathrm{SD}, \mathrm{n}=50)$, and $\mathrm{CGP}(3.5 \pm 7.7 \% \Delta \mathrm{F} / \mathrm{F}$, mean \pm SD, $n=59$ ), Kolmogorov-Smirnov, $\mathrm{p}=0.005, \mathrm{n}=109,5$ PNs. 
bioRxiv preprint doi: https://doi.org/10.1101/2020.06.15.152496; this version posted June 15, 2020. The copyright holder for this preprint (which was not certified by peer review) is the author/funder, who has granted bioRxiv a license to display the preprint in perpetuity. It is made available under aCC-BY 4.0 International license.

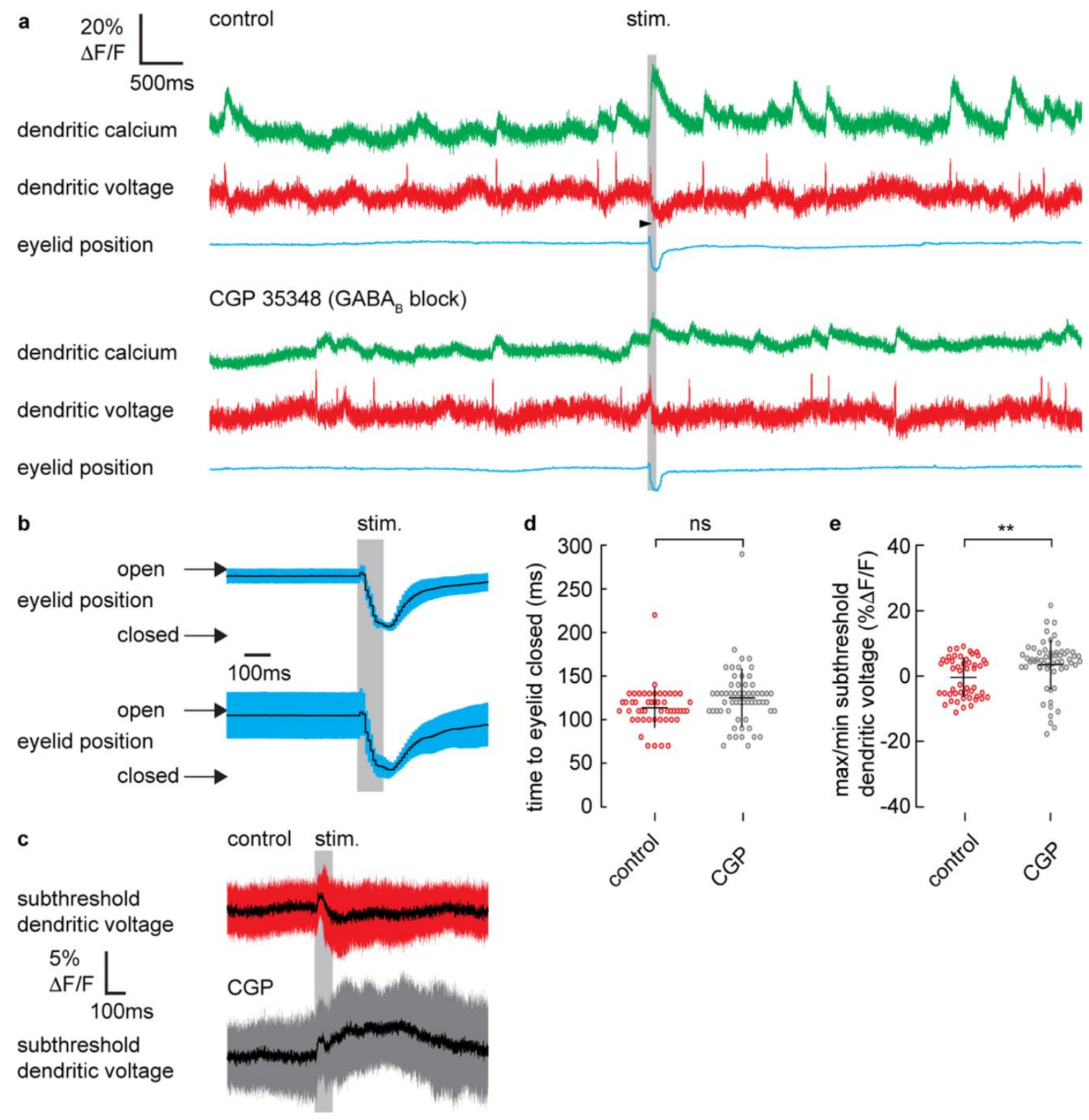

313 Figure 4. $\mathrm{GABA}_{\mathrm{B}}$ receptor antagonist, CGP 35348, blocks stimulus evoked hyperpolarizing dendritic voltage 314 signaling. (a) Single trial recordings of simultaneous dendritic voltage (red traces) and calcium (green traces) 315 during sensory stimulation (stim.). Blue traces show average intensity of ROI used to record eyelid position 316 (eyeblink responses). Grey bars show full duration of air puff stimulus. Top example shows voltage and calcium 317 recordings during control conditions (black arrow indicates a hyperpolarizing signal towards the end of the 318 stimulus), and bottom example shows recordings following CGP application from the same PN. Note there was 319 a relative increase in baseline GCaMP6f fluorescence of $93 \pm 90 \% \Delta \mathrm{F} / \mathrm{F}$, following CGP application. (b) 320 Mean eye responses from control (top) and CGP (bottom) recordings (black trace shows mean; blue trace shows 321 SD). (c) Average subthreshold voltage (spikelets removed) under control ( $\mathrm{n}=50)$ and CGP $(\mathrm{n}=59)$ conditions.

322 Note that $\mathrm{GABA}_{\mathrm{B}}$ blockade reveals a sustained sensory evoked depolarizing voltage (black traces show mean; 323 colored traces show SD). (d) Time for eyelid to close after stimulus onset under control (red) and CGP (grey) 324 conditions. (e) Maximum or minimum subthreshold voltage measured within a 200ms window after stimulus onset under control and CGP conditions. ** $\quad$ p $<0.01$. 
Sensory evoked stimulation has previously been shown to trigger enhanced calcium signals in PN dendrites of the cerebellar vermis, compared to spontaneous calcium signals

328 (Najafi et al., 2014b). Various mechanisms have been proposed to modulate suprathreshold 329 dendritic calcium signals in PNs, including molecular layer interneuron activity (Callaway et 330 al., 1995; Gaffield et al., 2018; Kitamura and Häusser, 2011), granule cell activity (Najafi et 331 al., 2014a, b) and graded CF input (Gaffield et al., 2019). However, the dendritic suprathreshold voltage signals that trigger these calcium signals have not been directly explored in awake animals. Thus, we next examined suprathreshold dendritic voltage signaling evoked by sensory stimulation (Figure 5).

As described previously (Roome and Kuhn, 2018), we detected two types of suprathreshold signals in the PN spiny dendrites; CF evoked DCS, which occurred at a reliable average rate of $1.05 \pm 0.4 \mathrm{~Hz}$ (mean $\pm \mathrm{SD}, 54 \mathrm{PNs}, 696$ recordings) and $\mathrm{PF}$ evoked DS, which occurred irregularly at an average rate of $0.13 \pm 0.3 \mathrm{~Hz}$ (mean $\pm \mathrm{SD}, 54 \mathrm{PNs}, 696$ recordings. Importantly, we detected an increase in frequency of both DCS and DS suprathreshold signals during the sensory stimulus (Figure 5a). Peri-stimulus time histograms (PSTH) for suprathreshold DCS and DS signals (Figure 5b), show how their frequency

343 increased dramatically during the sensory stimulus. Average DCS and DS frequencies during 344 the stimulus was $5.73 \pm 5.51 \mathrm{~Hz}$ and $1.24 \pm 0.77 \mathrm{~Hz}$ (mean $\pm \mathrm{SD}$ ), respectively; a relative 345 increase in DCS and DS frequency of 5.5 and 9.5 respectively (see Figure $5 b$ inset). The 346 average timing of DCS and DS signals after stimulus onset was $43.3 \pm 22.1 \mathrm{~ms}$ (mean $\pm \mathrm{SD}$, $\mathrm{n}=414)$ and $53.3 \pm 24.5 \mathrm{~ms}($ mean $\pm \mathrm{SD}, \mathrm{n}=92)$ respectively. 
bioRxiv preprint doi: https://doi.org/10.1101/2020.06.15.152496; this version posted June 15, 2020. The copyright holder for this preprint (which was not certified by peer review) is the author/funder, who has granted bioRxiv a license to display the preprint in perpetuity. It is made available under aCC-BY 4.0 International license.

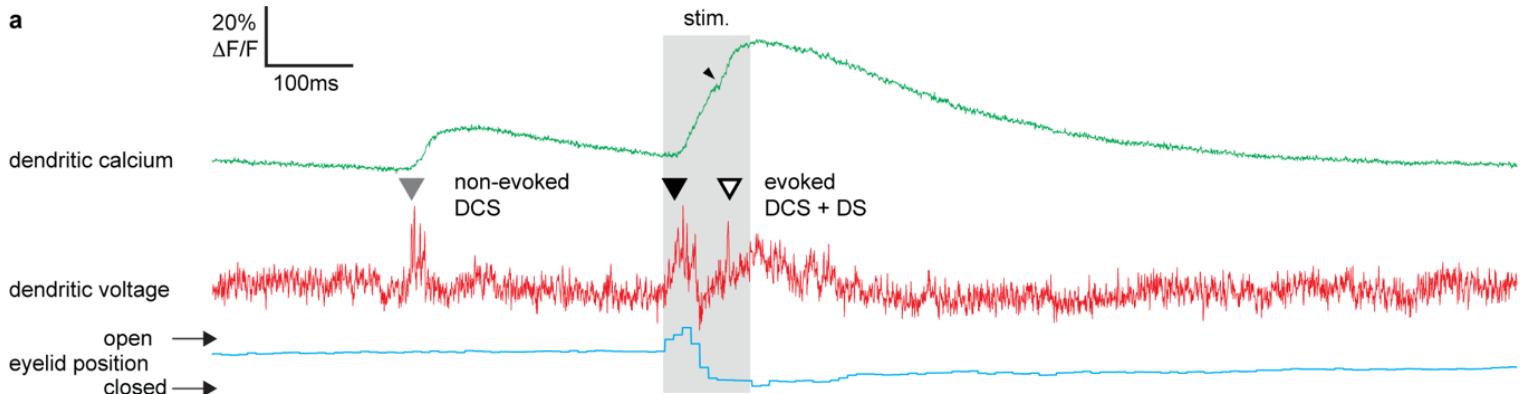

b

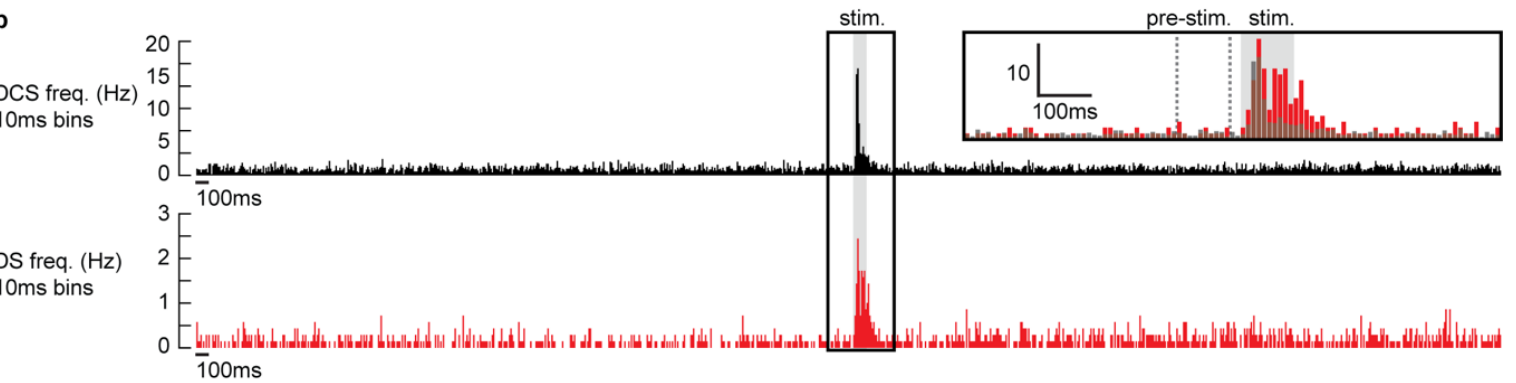

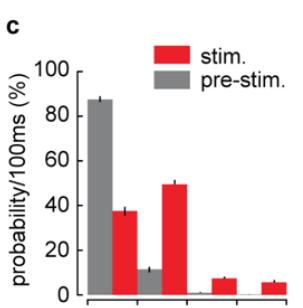

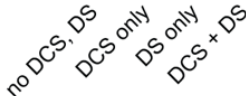

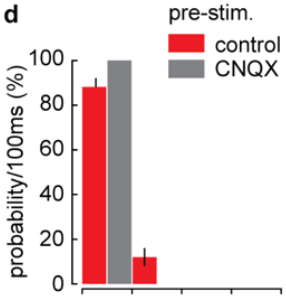

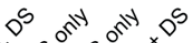

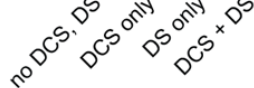

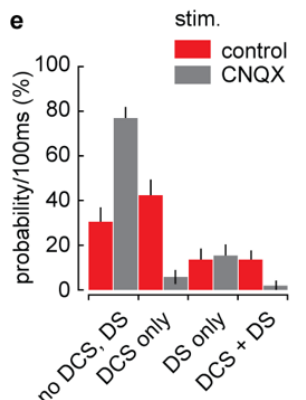

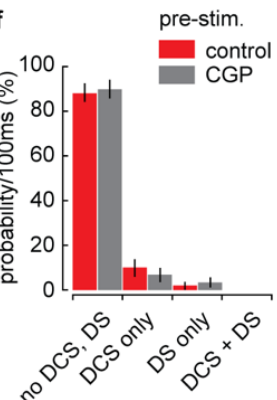

Figure 5. Suprathreshold calcium spikes are triggered by $\mathrm{CF}$ and PF synaptic input during sensory evoked responses. (a) A simultaneous recording of dendritic calcium (green trace) and voltage (red trace) during air puff sensory stimulation, showing DCS (filled triangle) and DS (open triangle) signals. Signals that occur during the air puff stimulus (stim.) are termed 'evoked' (black triangle), otherwise 'non-evoked' (grey triangle). Small black arrowhead indicates increase in calcium signal following the DS. Corresponding eyelid response (blue trace), timing of air puff stimulus (gray bar).

(b) PSTH for DCS frequency (top black) and DS frequency (bottom red) using 10ms bins. Inset shows zoomed overlay of DCS (black) and DS (red) frequencies, relative to their average frequencies. Dashed grey lines indicate the pre-stimulus period $(100 \mathrm{~ms}$ window prior to air puff onset). (c) Probability distributions for all possible outcomes; 'no DCS, DS', 'DCS only', 'DS only', and paired 'DCS + DS', during pre-stimulus and stimulus time windows. Probability distributions for suprathreshold DCS and DS signals during pre-stimulus (d) and stimulus (e) time windows, under control and CNQX conditions. Probability distributions for suprathreshold DCS and DS signals during pre-stimulus (f) and stimulus (g) time windows, under control and CGP conditions. Vertical bars in probability distributions show bootstrapped SD. 
We compared suprathreshold signals in a pre-stimulus time window $(100 \mathrm{~ms}$ window prior to stimulus onset, see Figure $5 \mathrm{~b}$ inset) with the stimulus time window, in all recordings and calculated the probability for the following outcomes; 'no DCS, DS', 'DCS only', 'DS only', and paired 'DCS + DS' (Figure 5c). There was a dramatic increase in the probability of detecting suprathreshold signals during the stimulus compared to the pre-stimulus time window; DCS only (pre-stimulus: $11.5 \pm 1.2 \%$, stimulus: $49.3 \pm 1.7 \%$ ); DS only (prestimulus: $0.8 \pm 0.4 \%$, stimulus: $7.6 \pm 1.1 \%$ ); paired DCS + DS signals (pre-stimulus: $0.3 \pm$ $0.2 \%$, stimulus: $5.9 \pm 0.9 \%$ ) (mean $\pm \mathrm{SD}, \mathrm{n}=688$, Kolmogorov-Smirnov, $\mathrm{p}=7.3 \times 10^{-79}$ ). CNQX application blocked suprathreshold DCS and DS signals. Probability distributions for suprathreshold DCS and DS signals during pre-stimulus time windows and during the stimulus, under control and CNQX conditions are shown in Figure 5d and Figure 5e, respectively. There were no suprathreshold signals detected during the pre-stimulus time window following CNQX application, and probability distributions were shifted towards a higher probability of 'no-signal' following CNQX application during the stimulus time window, Kolmogorov-Smirnov, $\mathrm{p}=1.6 \times 10^{-5}, \mathrm{n}=91,5$ PNs. Conversely, CGP application did not significantly alter the probability of suprathreshold signals, during either pre-stimulus or stimulus time windows (Figure $5 \mathrm{f}$ and Figure 5g, respectively), Kolmogorov-Smirnov, pre-stimulus; $\mathrm{p}=1.0$, stimulus; $\mathrm{p}=0.22, \mathrm{n}=109,5$ PNs.

In agreement with previous studies (Gaffield et al., 2019; Najafi et al., 2014b), we found that average evoked calcium signals (i.e. signals triggered during the stimulus) were enhanced relative to non-evoked calcium signals (i.e. signals occurring before the stimulus), (relative calcium peak; $1.4 \pm 0.6,51 \mathrm{PNs}, 365$ recordings, $\mathrm{t}$-test, $\mathrm{p}=1.5 \times 10^{-5}$ ), (Figure 1 figure supplement 5). To determine the mechanisms underlying the enhanced calcium signals, it is necessary to consider the suprathreshold voltage signals that trigger them.

To do this we examined the individual suprathreshold signals. Suprathreshold dendritic voltage spikelets and calcium signals detected during the stimulus (termed 'evoked' signals), were compared with signals detected prior to the stimulus (termed 'non-evoked' signals). We counted the total number of spikelets detected in a $100 \mathrm{~ms}$ window following each evoked or non-evoked DCS signal, including any additional DCS and DS signals within that time window, and measured the resulting calcium signal peak. Calcium peaks were on average larger following evoked DCS signals compared to the non-evoked DCS signals (nonevoked: $12.6 \pm 9.3 \% \Delta \mathrm{F} / \mathrm{F}, \mathrm{n}=1624$, evoked: $20.8 \pm 15.1 \% \Delta \mathrm{F} / \mathrm{F}, \mathrm{n}=333$, mean $\pm \mathrm{SD}$, 
bioRxiv preprint doi: https://doi.org/10.1101/2020.06.15.152496; this version posted June 15, 2020. The copyright holder for this preprint (which was not certified by peer review) is the author/funder, who has granted bioRxiv a license to display the preprint in perpetuity. It is made available under aCC-BY 4.0 International license.

396

397

398

399

400

401

402

403

404

405

406

407

408

409

410

411

412

413

414

415

416

417

418

unpaired t-test, $\mathrm{p}=1.6 \times 10^{-37}$ ) (Figure 6a). Accordingly, the corresponding dendritic voltage recordings showed an increase in the total number of dendritic spikelets following each evoked DCS signal compared to non-evoked DCS signals, evident through a positive shift in spikelet count probability distribution (Kolmogorov-Smirnov, $\mathrm{p}=1.85 \times 10^{-5}$ ) (Figure 6b).

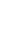

(1)
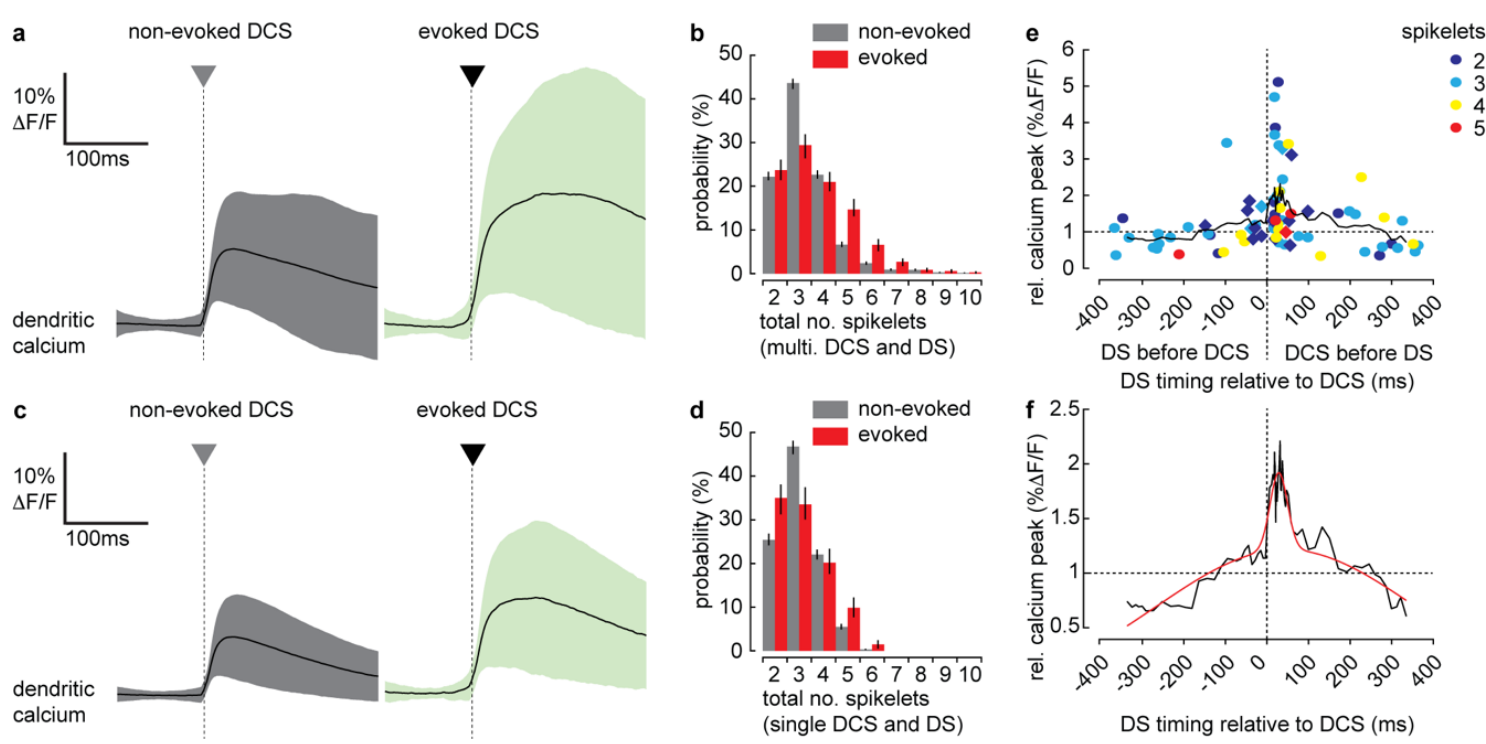

Figure 6. Supra-linear relationship between the timing of DCS and DS signals and their corresponding calcium signals. (a) Averages of all calcium signals following non-evoked (grey, left) and evoked (green, right) DCS signals. Black trace is mean and colored trace is SD. (b) Probability distributions for the total number of dendritic spikelets detected in a 100ms window following onset of each non-evoked and evoked DCS signal. (c) Averages of all calcium signals following non-evoked (grey, left) and evoked (green, right) DCS signals, excluding multiple DCS signals. Black trace is mean and colored trace is SD. (d) Probability distributions for the total number of dendritic spikelets detected in a 100ms window following onset of each non-evoked and evoked DCS signal, excluding multiple DCS signals. (e) Relationship between DCS + DS pair timing and the corresponding relative calcium peak. Relative calcium peaks were calculated with respect to the average calcium signal of DCS with the same number of spikelets (but with no paired DS signal). Colors represent the number of DCS spikelets for each DCS + DS pair. Data points for evoked DCS + DS pairs are diamonds and non-evoked DCS + DS pairs are circles. Black line shows boxcar average of 10 consecutive data points and (f) two-term gaussian fit (red line) applied to boxcar average (adjusted r-square $=0.9117$ ). Vertical bars in probability distributions show bootstrapped SD. 
We considered the possibility that the increase in dendritic calcium peak and the number of spikelets result from an increase in the number of $\mathrm{CF}$ inputs (i.e. multiple DCS signals) within the $100 \mathrm{~ms}$ time window. Due to slow calcium indicator dynamics, high frequency CF inputs cannot always be resolved from the calcium signal alone (see Figure 1 figure supplement $2 \mathrm{c}$ ). Using the voltage recording we detected and excluded all signals in which multiple CF inputs were observed and repeated the analysis. Interestingly, when only single DCS signals were permitted, the peak calcium of evoked signals remained enhanced compared to non-evoked signals (non-evoked: $11.9 \pm 8.1 \% \Delta \mathrm{F} / \mathrm{F}, \mathrm{n}=1292$, evoked: $19.7 \pm$ $14.2 \% \Delta \mathrm{F} / \mathrm{F}, \mathrm{n}=203$, mean $\pm \mathrm{SD}$, unpaired t-test, $\mathrm{p}=3.8 \times 10^{-28}$ ) (Figure 6c). However, the difference between pre-stimulus and stimulus probability distributions of spikelet numbers was no longer significant (Kolmogorov-Smirnov, $p=0.075$ ) (Figure 6d), indicating that the enhanced calcium signal was not exclusively due to an increase in CF input frequency, or even due to an increase in dendritic spiking, caused by stronger CF input alone.

Since both DCS and DS frequency increased during the sensory stimulus, we next considered the possibility that enhanced evoked calcium signals result from paired DCS and DS signals that occur during the same stimulus. We investigated the relationship between the timing of paired DCS + DS signals and their corresponding dendritic calcium signal, by selecting all DCS + DS pairs (non-evoked and evoked) with $<400 \mathrm{~ms}$ temporal separation. We measured the calcium peak following each pair of DCS + DS signals, relative to the average calcium peak of a single DCS signal comprising the same number of spikelets. Relative calcium peaks were plotted in relation to the temporal separation of each DCS + DS pair (Figure 6e). Analysis revealed a clear asymmetric and supra-linear relationship between the timing of DCS and DS signals and their corresponding calcium signals. By fitting a twoterm gaussian function (Figure 6f) we estimate that the average relative calcium peak is maximum when DS follow DCS signals by $28.3 \pm 5.4$ ms (mean \pm SD). input act to enhance the dendritic calcium signal. However, paired DCS + DS signals are relatively rare (detected in only $5.9 \pm 0.9 \%$ of recordings), suggesting an additional coincidence detection mechanism at work. Taken together, our findings thus far reveal an 450 increase in both sub- and suprathreshold dendritic signaling during sensory stimulation. These signals originate primarily from coincident PF and CF synaptic input, because the 
subthreshold signals are predominantly depolarizing, and suprathreshold dendritic signals are triggered exclusively by excitatory $\mathrm{CF}$ and PF synaptic input.

Supra-linear dendritic signaling in PN dendrites during sensory evoked stimulation is voltage and mGluR1 dependent

To investigate the mechanisms underlying evoked supra-linear calcium signals further, we selected individual evoked and non-evoked DCS signals only (now with no

460 subsequent DCS or DS signals). We sorted DCS signals based on the number of spikelets 461 generated. This created four DCS groups, ranging from 2 to 5 spikelets) (Figure 7a-c). 462 Averaging voltage traces within each evoked spikelet group revealed a prominent 463 subthreshold depolarization beginning before the evoked DCS signals, this 'pre-DCS' signal 464 was not detected preceding non-evoked DCS signals (black arrowheads in Figure 7c). This 465 would be expected because on average, sensory evoked subthreshold signals are depolarizing 466 and precede DCS generation (as shown in Figure 2 and Figure 6). Average pre-DCS voltages 467 (measured in a $10 \mathrm{~ms}$ window preceding DCS signals) for each group are shown in Figure 7d 468 (evoked pre-DCS vs. non-evoked pre DCS, ANOVA, $\mathrm{p}<0.004$ ). The evoked pre-DCS 469 depolarization amplitude was independent of number of DCS spikelets (2 spikelets: $1.31 \pm$ $470 \quad 1.84 \% \Delta \mathrm{F} / \mathrm{F} ; 3$ spikelets: $1.35 \pm 1.93 \% \Delta \mathrm{F} / \mathrm{F} ; 4$ spikelets: $1.47 \pm 2.22 \% \Delta \mathrm{F} / \mathrm{F} ; 5$ spikelets: $1.29 \pm 1.14 \% \Delta \mathrm{F} / \mathrm{F}$, mean $\pm \mathrm{SD}$, ANOVA, $\mathrm{p}>0.52$ ) (Figure 7e).

472 
bioRxiv preprint doi: https://doi.org/10.1101/2020.06.15.152496; this version posted June 15, 2020. The copyright holder for this preprint (which was not certified by peer review) is the author/funder, who has granted bioRxiv a license to display the preprint in perpetuity. It is made available under aCC-BY 4.0 International license.

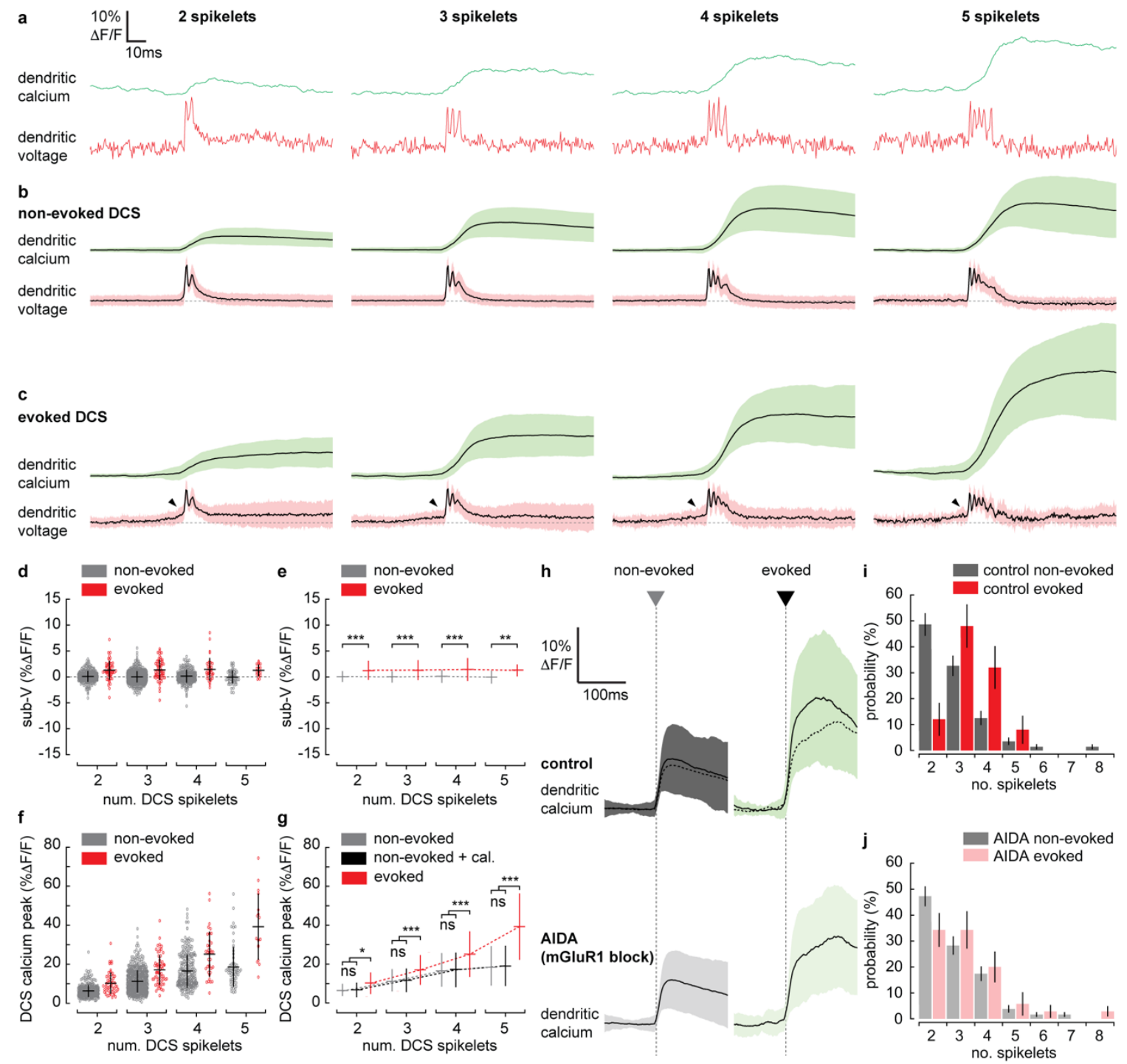

475 Figure 7. Supra-linear dendritic signaling in PN dendrites during sensory evoked stimulation is voltage and mGluR1 dependent. (a) Single trial examples of non-evoked DCS signals sorted based on the number of spikelets showing dendritic voltage (red traces) and calcium (green traces). (b) Averages of all non-evoked DCS signals. (c) Averages of all evoked DCS signals. Arrowheads indicate subthreshold depolarization preceding evoked DCS signals. (d) Average subthreshold pre-DCS voltage for evoked (red) and non-evoked (grey) signals, grouped based on the number of DCS spikelets. Horizontal bars show mean, vertical bars show SD. (e)

481 Mean from all groups in (d). (f) Average calcium peak for evoked (red) and non-evoked (grey) signals, grouped 482 based on the number of DCS spikelets. (g) Mean from all groups in (f) and sum of non-evoked and + cal. groups 483 (black). (h) Averages of all calcium signals following non-evoked (grey, left) and evoked (green, right) DCS signals, under control (top dark traces) and mGluR1 block (AIDA) conditions (bottom light traces and top overlaid dashed traces). Black trace is mean and colored trace is SD. Probability distributions for the total number of dendritic spikelets detected in a 100ms window following onset of each non-evoked and evoked DCS signal, excluding multiple DCS signals, under (i) control and (j) mGluR1 block conditions (KolmogorovSmirnov, vertical bars in probability distributions show bootstrapped SD). $* \mathrm{p}<0.05$, ** $\mathrm{p}<0.01$ and $* * * \mathrm{p}<$ 0.001 . 
We would expect the subthreshold depolarization detected during evoked signals to contribute to the calcium signal through the voltage-dependent increase in calcium baseline

493 that we described in Figure $1 \mathrm{j}$. Using the sub-threshold voltage-calcium relationship 494 determined in Figure1j, and the average pre-DCS voltage across all spikelet groups; $1.36 \pm$ $1.89 \% \Delta \mathrm{F} / \mathrm{F}$ (approximately $2.7 \pm 3.8 \mathrm{mV}$, mean $\pm \mathrm{SD}$ ), we would predict an average increase in calcium baseline of $0.8 \% \pm 1.5 \% \Delta \mathrm{F} / \mathrm{F}$.

In reality, the average calcium peak was much larger during evoked DCS signals compared to non-evoked DCS signals comprising the same number of spikelets. Furthermore, the difference between evoked and non-evoked calcium peaks increased supra-linearly with the number of DCS spikelets (non-evoked vs. evoked, 2 spikelets: $6.2 \pm 3.2 \% \Delta \mathrm{F} / \mathrm{F}$ vs. 10.1 $\pm 5.5 \% \Delta \mathrm{F} / \mathrm{F} ; 3$ spikelets: $11.1 \pm 5.7 \% \Delta \mathrm{F} / \mathrm{F}$ vs. $17.0 \pm 7.7 \% \Delta \mathrm{F} / \mathrm{F} ; 4$ spikelets: $16.4 \pm 8.6 \%$ $\Delta \mathrm{F} / \mathrm{F}$ vs. $25.1 \pm 11.7 \% \Delta \mathrm{F} / \mathrm{F} ; 5$ spikelets: $18.5 \pm 10.2 \% \Delta \mathrm{F} / \mathrm{F}$ vs. $39.3 \pm 17.1 \% \Delta \mathrm{F} / \mathrm{F}$, mean $\pm \mathrm{SD}$, ANOVA, $\mathrm{p}<0.002$ ) (Figure 7f). In this case, the linear sum of non-evoked DCS calcium peak and our predicted increase in calcium baseline ('+ cal.') could not account for the supra-linear enhancement in calcium peak during evoked DCS signals (non-evoked + cal. vs. evoked, ANOVA, $\mathrm{p}<0.043$ ) (Figure 7g).

Activation of mGluR1s by coincident PF and CF input is known to drive supra-linear calcium signals at PF-PN synapses in cerebellar slices (Wang et al., 2000), but their contribution to PN dendritic signaling has not been explored in vivo. By application of AIDA (a potent and selective mGluR1 antagonist), we assessed the contribution of mGluR1 to

513 sensory evoked dendritic signals in the awake mouse. After application of AIDA, sensory 514 evoked calcium signals were significantly reduced (control: $24.4 \pm 12.3 \% \Delta \mathrm{F} / \mathrm{F}$, AIDA: 17.9 $515 \pm 9.3 \% \Delta \mathrm{F} / \mathrm{F}$, mean $\pm \mathrm{SD}$, unpaired t-test, $\mathrm{p}=0.025)$ (Figure $7 \mathrm{~h}$ ). Non-evoked calcium 516 signals however were not significantly altered (control: $10.6 \pm 6.5 \% \Delta \mathrm{F} / \mathrm{F}$, AIDA: $9.5 \pm 5.5$ $517 \% \Delta \mathrm{F} / \mathrm{F}$, mean $\pm \mathrm{SD}$, unpaired t-test, $\mathrm{p}=0.116$ ), indicating that the contribution of mGluR1 518 activity to the calcium signal is specific to sensory evoked calcium signals when $\mathrm{CF}$ and $\mathrm{PF}$ 519 inputs coincide, and we propose that mGluR1s are activated at PF-PN synapses, where the PF 520 and CF synaptic potentials converge. 
Probability distributions for suprathreshold signals detected in pre-stimulus and

523 stimulus time windows were calculated under control and AIDA conditions. As in Figure 5c,

524 there was a clear increase in signal probability during the stimulus compared to pre-stimulus

525 time windows under both control and AIDA conditions, but we detected no difference

526 between control vs. AIDA conditions (for either pre-stimulus or stimulus groups), indicating

527 that mGluR1 block did not directly affect CF and PF input (Figure 7 - figure supplement 1).

528 There was also no significant effect of AIDA on evoked subthreshold signaling, supporting

529 the conclusion that the subthreshold signals are predominantly AMPA mediated (Figure 7 -

530 figure supplement 1).

However, we found that the probability distribution for the total number of spikelets

533 following evoked DCS was shifted towards lower numbers under AIDA conditions.

534 Consequently, unlike control conditions (Figure 7i), the probability distributions for the total

535 number of spikelets following evoked and non-evoked DCS signals were no longer

536 significantly different following AIDA application (Figure 7j). This suggests that mGluR1

537 activity enhances spikelet generation during evoked DCS signals. Such an interaction

538 between mGluR1 activity and spikelet generation, has previously been postulated (Tempia et

539 al., 2001) and is likely mediated through their interaction with T and P/Q-type VGCCs

540 (Hildebrand et al., 2009; Otsu et al., 2014). 
Discussion:

Dendritic coincidence detection is a salient signal in neuronal processing. We used

544 simultaneous voltage and calcium two-photon imaging of single PN dendrites at high temporal resolution $(2 \mathrm{kHz})$ to explore $\mathrm{PF}$ and $\mathrm{CF}$ coincident input during sensory evoked responses. The ability to distinguish between sub- and suprathreshold signaling and dendritic spikes evoked by either $\mathrm{CF}$ or PF input has provided fresh insight into graded dendritic calcium signals evoked by sensory stimulation, and the integration of information transferred by coincident PF and CF input pathways.

Here we describe how PF and CF synaptic input to PN dendrites is integrated during sensory evoked stimulation in awake mice. To summarize, we identify three interplaying dendritic coincidence detection mechanisms that modulate calcium signals at the PN dendritic level. PN dendrites integrate PF and MLI evoked excitatory and inhibitory postsynaptic potentials, resulting in a subthreshold voltage-dependent calcium signal (Figure 1). The first mechanism of dendritic coincidence detection occurs if the subthreshold voltagedependent calcium signal (Figure 1j) coincides with a suprathreshold input. This is potentially the cause of the enhanced evoked calcium signals compared to non-evoked signals, while mGluR1 is blocked (Figure 7h). Previous in vitro studies have shown how membrane potential and timing of coincident sub- and suprathreshold synaptic input is critical for modulating calcium signaling and synaptic plasticity at PF-PN synapses (Ly et al., 2016; Sarkisov and Wang, 2008). The second mechanism is through PF evoked DS, whose frequency increases during the sensory stimulus and when paired with DCS, act to enhance the CF evoked calcium signal in a time-dependent manner (Figure 6). It is important to note that while PF evoked DS signals are relatively rare in awake mice (Roome and Kuhn, 2018), we found that their frequency increased 9.5 times during sensory stimulation, and their impact on the dendritic calcium signal was supra-linear. Thus, we propose PF evoked DS signals play a unique role in modulating dendritic calcium signals during sensory stimulation. In fact, the additional PF evoked DS could be viewed as a correction to the CF evoked DCS signal, supplementing an otherwise 'too weak' DCS signal with an extra dendritic spike. The third is through mGluR1 activity (Figure 7), which is known to trigger supra-linear calcium signals when PF and CF inputs are conjunctively activated, that modify PF-PN synaptic strength (Sarkisov and Wang, 2008; Wang et al., 2000). It is intriguing that the coincidence detection processes and supra-linear dendritic calcium signals we describe here, occur 
575 seemingly continuously; during sensory stimulation in awake naïve mice, and not only during

576 motor learning of a specific task, such as eyeblink conditioning.

577

$578 \quad$ PN dendrites and their spines are highly sensitive to calcium levels, which can in turn

579 determine the direction of synaptic plasticity at PF-PN synapses (Coesmans et al., 2004;

580 Jorntell and Hansel, 2006). We expect that to constantly finetune plasticity at PF-PN

581 synapses, calcium signals are continuously graded at the PN dendrite level, to permit a full

582 dynamic range. The coincident activity of CF and PF synaptic input (and also PF driven feed

583 forward inhibition via MLIs) combined with intrinsic dendritic mechanisms (VGCCs and

584 mGluR1s) allow for this high dynamic range in calcium signaling. Here, we establish that

585 their combined activity becomes more apparent during heightened sensory input, as indicated

586 by their enhanced cooperation during sensory evoked eyeblink responses. 
Methods:

Animals and surgery

590

All animal procedures were conducted in accordance with guidelines of the Okinawa

592 Institute of Science and Technology Institutional Animal Care and Use Committee in an

593 Association for Assessment and Accreditation of Laboratory Animal Care (AAALAC

594 International)-accredited facility. Cerebellar chronic cranial window surgeries were performed on 2-month-old male C57/BL6 mice, using a $5 \mathrm{~mm}$ glass cover slip with silicone access port (Roome and Kuhn, 2014). The window was positioned to allow imaging within lobule $\mathrm{V}$ of the cerebellar vermis and the access port was positioned to allow access to the imaging area via a micropipette for PN labelling and drug delivery.

\section{Microscope setup}

601

602

We used a custom-built combined wide-field, two-photon microscope (MOM, Sutter 603 Instruments) with either a $\times 5 /$ N.A. 0.13 air objective (Zeiss) or a $\times 25 /$ N.A. 1.05 water 604 immersion objective with $2 \mathrm{~mm}$ working distance (Olympus) with ScanImage software. 605 Bright field imaging was performed using a sCMOS camera (PCO.edge, PCO). A 606 femtosecond-pulsed Ti:sapphire laser (Vision II, Coherent), circularly polarized and under607 filling the back focal plane of the $\times 25$ objective, was used to excite fluorescence (typical laser 608 power at $1020 \mathrm{~nm}: 60 \mathrm{~mW}$ ), which was detected by two GaAsP photomultiplier tubes 609 (Hamamatsu) in the spectral range of 490-550 nm (green: GCaMP6f) and 550-750 nm (red: 610 ANNINE-6plus).

611 The mice were headfixed on a platform that consisted of a vertically rotating 612 treadmill, head-plate stage and micromanipulator tower (Sutter Instruments), all mounted on 613 a horizontally rotating stage (8MR190-90-4247, Standa). The sCMOS camera and infrared 614 light source were used to record behavioral activity during recording at $100 \mathrm{fps}$. A second 615 infrared video camera (Sony) was used to monitor mouse behavior throughout the 616 experiment. The micromanipulator (M-285, Sutter instruments) was used for GCaMP6f virus 617 (UPenn Vector Core) and ANNINE-6plus dye (www.sensitivefarbstoffe.de, Dr. Hinner and 618 Dr. Hübener Sensitive Dyes GbR) injection and also for drug delivery and 619 electrophysiological recording via micropipette. 


\section{AAV injections}

One week following surgery, mice were anesthetized (1-2\% Isoflurane) and head mounted for two-photon guided injection of the adeno-associated viral vectors (AAVs) into the PN layer approximately $150 \mu \mathrm{m}$ below the dura. For this, beveled quartz electrodes (0.7 mm ID, pulled and beveled to $10-20 \mu \mathrm{m}$ tip diameter) containing AAV1.hSyn.Cre (2E13 GC/ml), AAV1.CAG.Flex.GCaMP6f $(1.3 \mathrm{E} 13 \mathrm{GC} / \mathrm{ml})$, and $50 \mu \mathrm{M}$ FITC in PBS at a ratio of 1:1:1 were used to specifically target PNs and visually control the position and size of the viral injection, while $<0.1$ PSI pressure was used to inject the virus for $1 \mathrm{~min}$. After virus injection the pipette was retracted, and the mouse was returned to its cage.

\section{Single neuron labelling with ANNINE-6plus}

634

One week after virus injection, GCaMP6f-expressing PNs were targeted for voltagesensitive dye (ANNINE-6plus) single-cell labelling by electroporation, guided by two-photon microscopy (Kuhn and Roome, 2019). GCaMP6f-expressing PN were electroporated using a patch pipette containing $3 \mathrm{mM}$ ANNINE-6plus dissolved in ethanol. Borosilicate glass (patch) pipettes with $1 \mu \mathrm{m}$ tip diameter (7-10 M 2 ) were used for electroporation and a stimulus protocol of 50 negative current pulses $(-30 \mu \mathrm{A}), 1 \mathrm{~ms}$ in duration at $100 \mathrm{~Hz}$ were delivered. Neutral pressure was applied to the patch pipette to prevent leakage of the dye/ethanol solution into tissue and the pipette was retracted immediately after the cell was loaded and replaced for further single-neuron labelling.

Typically, two to five PNs were filled per mouse on the same day, and after loading PNs with dye, mice were returned to their cages to allow the dye to spread to distal dendrites and throughout the entire cell. ANNINE-6plus is highly lipophilic so dye diffusion can take several hours $(>12 \mathrm{~h})$. After $\sim 20 \mathrm{~h}$, the brightest labelled cells were selected for imaging experiments, which were performed the day following PN labelling. This also guaranteed that the PN was healthy and had not been damaged by the labelling procedure. Where possible, several PNs were labelled in the same mouse (up to 5) and used for simultaneous dendritic voltage and calcium imaging recordings. Between neuron labelling sessions and following surgery, mice were returned to their cages and allowed to recover. 

dendrites was performed $(<50 \mu \mathrm{m}$ below dura) in linescan mode at $2 \mathrm{kHz}$ sampling rate.

660 Labelled PNs were clearly visible in both red and green channels indicating successful 661 labelling with ANNINE-6plus and GCaMP6f. During recordings, mice were alert and 662 headfixed sitting on a rotating treadmill. Mice were allowed to sit awake on the treadmill for at least 30 minutes before beginning the experiment. Bidirectional linescans, 512 pixels in width, lasting $10.5 \mathrm{~s}$ were performed at a line rate of $2 \mathrm{kHz}$. To limit photo-damage during linescans and to improve signal-to-noise ratio, the objective collar was rotated to elongate the excitation volume predominantly in the z-direction to $\sim 5 \mu \mathrm{m}$. During the $10.5 \mathrm{~s}$, no bleaching was observed. Fine corrections in linescan orientation (with respect to PN dendrites) were done prior to the experiment using the rotating stage, on which the mouse treadmill and micro-manipulators were placed. The linescans measuring $256 \mu \mathrm{m}$ in width were carefully positioned as superficial as possible as to include the full dendritic width of the most distal dendritic spiny PN branches, thus maximizing the total membrane area covered by the linescan, typically less than $50 \mu \mathrm{m}$ below the pia mater. ANNINE-6plus is purely electrochromic, showing linear responses across the full physiological voltage range and is well suited for recording neuronal membrane potential, with a temporal resolution limited only by the fluorescence lifetime (Fromherz et al., 2008). The femtosecond-pulsed Ti:sapphire laser was used to excite fluorescence at $1020 \mathrm{~nm}$, near the red spectral edge of absorption. To confirm optimal ANNINE-6plus sensitivity near the red spectral edge of absorption and the mechanism of voltage sensitivity (Kuhn et al., 2004), different excitation wavelengths were tested (Roome and Kuhn, 2018). Excitation near the red spectral edge of absorption to optimize voltage sensitivity allows for long-term simultaneous voltage and calcium dendritic recordings at least $500 \mathrm{~s}$ per recording session at different dendritic depths. As ANNINE-6plus is relatively hydrophobic compared to other voltage-sensitive dyes for intracellular application, the labelling lasts for at least 2 weeks (Roome and Kuhn, 2018, 2019). Due to an extended excitation point spread function $\left(\sim 1 \times 1 \times 5 \mu \mathrm{m}^{3}\right)$ used to increase the signal-to-noise ratio, the voltage signal is the average membrane potential in this volume encompassing spines and dendritic shafts. 


\section{Pharmacology}

A micropipette inserted through the chronic cranial window access port was used for

694 pharmacological manipulation. In this case, the micropipette: a beveled quartz micropipette

695 (0.7 mm ID, Sutter Instruments) was placed $\sim 50 \mu \mathrm{m}$ below the PN soma for drug injections.

696 Lidocaine (2\%) (Sigma) and CNQX disodium salt $(100 \mu \mathrm{M})$ (Tocris) were used to block $\mathrm{Na}^{+}$ 697 channels and AMPA receptors (excitatory synaptic input) respectively. CGP $35348(100 \mu \mathrm{M})$

698 (Tocris) was used to block $\mathrm{GABA}_{\mathrm{B}}$ receptors. $\mathrm{GABA}_{\mathrm{B}}$ receptors are predominantly localized

699 to the imaging region (PF-PN synapses in the spiny dendrites) (Kulik et al., 2002), whereas

$700 \mathrm{GABA}_{\mathrm{A}}$ receptors are expressed abundantly throughout the cerebellum, notably at basket cell

701 terminals on the PN soma (Fritschy and Panzanelli, 2006). Blocking $\mathrm{GABA}_{\mathrm{A}}$ receptors with

702 SR 95531 hydrobromide $(100 \mu \mathrm{M})$ (Tocris) led to over-excitability of the PN dendrites and 703 irregular spontaneous spiking behavior. AIDA $(100 \mu \mathrm{M})$ (Tocris) was used to block mGluR1 704 activity. All drugs were dissolved in saline and applied by pressure injection $(<0.5 \mathrm{psi})$ for $70510 \mathrm{~min}$ prior to imaging and reduced to $<0.1 \mathrm{psi}$ while dendritic voltage and calcium 706 recordings were repeated in the awake mice. Dendritic recordings were occasionally repeated $707 \sim 24 \mathrm{~h}$ after drug application (guaranteeing drug washout) to confirm that the labelled PN was not physically damaged by the drug application.

\section{Data analysis}

Linescan TIFF images were initially cropped in width using ImageJ (US National

713 Institute of Health) to contain only the dendrite from the labelled PN using the red channel as 714 a guide, and to eliminate green signals originating from neighboring PNs. Full linescan traces 715 were imported into Matlab and interpolated (from 2 to $10 \mathrm{kHz}$ ). All subsequent data analysis 716 was performed using custom-written programs that we wrote previously with Matlab 717 (MathWorks). Minor movement corrections were made to linescan images in the spatial 718 dimension, to minimize movement artefacts that occur during the sensory stimulus. This was 719 achieved by maximizing the cross correlation between the average pre-stimulus linescan spatial profile, and the spatial profile of individual lines collected during the stimulus.

Single unit electrophysiological recordings were analyzed using Spike2 spike 722 detection software (CED) to create a binary trace for simple spikes (SS) (and to eliminate 
spikes originating from neighboring PNs). All complex spikes (occurring at $\sim 1 \mathrm{~Hz}$ ) were easily identified by eye, which could be confirmed by comparing simultaneous electrophysiology, voltage and calcium traces. Complex spike binary traces were created using the initial sodium spike of the somatic complex spike to mark its onset. All binary traces, raw images and electrophysiology were then imported into Matlab for analysis.

To calculate $\Delta \mathrm{F} / \mathrm{F}$ of full linescans, the green channel image was first scaled (using Matlab 'regress' function) and fit to the red channel and then subtracted from the red channel. This removed crosstalk from the green channel. Average baseline red channel fluorescence was then subtracted from the time-varying red channel fluorescence and the result was divided by the average baseline of red channel fluorescence to give $\Delta \mathrm{F} / \mathrm{F}$ for the red channel. The $\Delta \mathrm{F} / \mathrm{F}$ calculation for the green channel was made in the same way as for the red channel, but it was not necessary to first subtract red channel fluorescence from the green channel as the voltage signal was neglectable compared to GCaMP6f. Relative fluorescence changes imaged with an excitation wavelength of $1020 \mathrm{~nm}$ were converted with a factor of $2.1 \mathrm{mV} / \%$ to estimate voltage changes.

\section{DCS and DS spikelet detection in Matlab}

DCS and single DS signals were detected using a custom-written program in Matlab. Spatially averaged voltage and calcium traces were first temporally filtered. Voltage traces were filtered using a 1ms boxcar filter, while calcium traces were filtered using a $10 \mathrm{~ms}$ boxcar filter. All spikelets were then detected in the voltage traces using the 'findpeaks' function in Matlab, for which 'MinPeakHeight' was set at 3 standard deviations of the voltage recording, the 'MinPeakDistance' was set at $2.5 \mathrm{~ms}$ and 'MinPeakProminence' was set at 1 standard deviation of the voltage recording. Spikelets were then sorted into DS or DCS signals based on the following criteria:

Spikelets were classed as DS signals if:

1. No additional spikelets were detected in a window of $\pm 10 \mathrm{~ms}$ prior to and following the spikelet (i.e. no burst of spikelets was detected).

2. The average corresponding calcium signal measured in a $20 \mathrm{~ms}$ window following the spikelet increased by $>1 \%$, compared to the average calcium signal measured in a $20 \mathrm{~ms}$ window prior to the spikelet (i.e. corresponding calcium signal was detected). 
3. The average voltage signal measured in a $10 \mathrm{~ms}$ window following the spikelet was less than 1 standard deviation of the voltage recording (i.e. the voltage recording returned immediately to baseline after a single spikelet).

Spikelets were classed as DCS signals if:

1. Additional spikelets were detected in a window of $\pm 10 \mathrm{~ms}$ prior to and following the spikelet (i.e. a burst of two or more spikelets were detected).

2. The average corresponding calcium signal measured in a $20 \mathrm{~ms}$ window following the spikelet increased by $>1 \% \Delta \mathrm{F} / \mathrm{F}$, compared to the average calcium signal measured in a $20 \mathrm{~ms}$ window prior to the spikelet (i.e. corresponding calcium signal was detected).

Classifications of DCS and DS signals were subsequently cross checked by visual inspection and though application of the classification algorithm, to paired dendritic and somatic recordings made on 7 PNs in awake mice (Roome and Kuhn, 2018), to confirm that DCS signals have a corresponding CF evoked somatic complex spike, while DS signals had no corresponding somatic signal (i.e. only dendritic) (see Figure 1 - figure supplement 2).

\section{Behavior analysis}

Behavioral recordings were made while the mouse was awake and sitting on a treadmill. A behavior camera (sCMOS), capturing frames at $100 \mathrm{~Hz}$, was used to record sensory stimulus evoked movements, synchronized with the imaging. Linescan recordings (10.5 seconds in length) included a 100ms sensory stimulus beginning after 5 seconds of recording, giving an air puff directed at the ipsilateral eye of the mouse. Air-puffs (pressure: 30psi) were delivered via a $(0.7 \mathrm{~mm}$ I.D) glass capillary positioned $2 \mathrm{~cm}$ from the eye to evoke a reliable eye blink reflex in the ipsilateral eye. Regions of interest (ROIs) were drawn around the ipsilateral eye and the $\Delta$ intensity/intensity was used to quantify eyelid position and closure during the stimulus, and traces were normalized such that 1 and 0 correspond to the maximum and minimum eyelid closure recorded for each mouse across all recordings, in order to monitor changes in the eye response over time. 


\section{Acknowledgments:}

We thank the GENIE Program and the Janelia Research Campus for distributing

790 GCaMP6f, Lina Koronfel and Soumen Jana for helpful feedback on the manuscript. We are

791 grateful for generous support and funding from the Okinawa Institute of Science and

792 Technology Graduate University.

793

794 Author contributions:

795 C.J.R. designed the study, built the setup, collected and analyzed data, and wrote the paper.

796 B.K. designed the study, built the setup, and wrote the paper.

797

\section{Competing Interests:}

799 The authors declare no competing financial interests. 
References:

801

802 Ait Ouares, K., and Canepari, M. (2020). The Origin of Physiological Local mGluR1 Supralinear $\mathrm{Ca}(2+)$ Signals in Cerebellar Purkinje Neurons. J Neurosci 40, 1795-1809.

804

805

Brown, T.H., Kairiss, E.W., and Keenan, C.L. (1990). Hebbian synapses: biophysical mechanisms and algorithms. Annu Rev Neurosci 13, 475-511.

807

Callaway, J.C., Lasser-Ross, N., and Ross, W.N. (1995). IPSPs strongly inhibit climbing fiberactivated $[\mathrm{Ca} 2+] i$ increases in the dendrites of cerebellar Purkinje neurons. J Neurosci 15, 2777-2787.

Coesmans, M., Weber, J.T., De Zeeuw, C.I., and Hansel, C. (2004). Bidirectional parallel fiber plasticity in the cerebellum under climbing fiber control. Neuron 44, 691-700.

814

Fritschy, J.M., and Panzanelli, P. (2006). Molecular and synaptic organization of GABAA receptors in the cerebellum: Effects of targeted subunit gene deletions. Cerebellum 5, 275285.

818

Fromherz, P., Hübener, G., Kuhn, B., and Hinner, M.J. (2008). ANNINE-6plus, a voltagesensitive dye with good solubility, strong membrane binding and high sensitivity. European biophysics journal : EBJ 37, 509-514.

Gaffield, M.A., Bonnan, A., and Christie, J.M. (2019). Conversion of Graded Presynaptic Climbing Fiber Activity into Graded Postsynaptic $\mathrm{Ca}(2+)$ Signals by Purkinje Cell Dendrites. Neuron 102, 762-769 e764.

Gaffield, M.A., Rowan, M.J.M., Amat, S.B., Hirai, H., and Christie, J.M. (2018). Inhibition gates supralinear $\mathrm{Ca}(2+)$ signaling in Purkinje cell dendrites during practiced movements. Elife 7.

830

Hildebrand, M.E., Isope, P., Miyazaki, T., Nakaya, T., Garcia, E., Feltz, A., Schneider, T., Hescheler, J., Kano, M., Sakimura, K., et al. (2009). Functional coupling between mGluR1 and Cav3.1 T-type calcium channels contributes to parallel fiber-induced fast calcium signaling within Purkinje cell dendritic spines. J Neurosci 29, 9668-9682.

Jorntell, H., and Hansel, C. (2006). Synaptic memories upside down: bidirectional plasticity at cerebellar parallel fiber-Purkinje cell synapses. Neuron 52, 227-238. and sensory-evoked climbing fiber input to cerebellar Purkinje cells in vivo. J Neurosci 31, 10847-10858. 
Kuhn, B., Fromherz, P., and Denk, W. (2004). High sensitivity of Stark-shift voltage-sensing dyes by one- or two-photon excitation near the red spectral edge. Biophysical journal 87, 631-639.

Kuhn, B., and Roome, C.J. (2019). Primer to Voltage Imaging With ANNINE Dyes and TwoPhoton Microscopy. Front Cell Neurosci 13, 321.

853

Kulik, A., Nakadate, K., Nyiri, G., Notomi, T., Malitschek, B., Bettler, B., and Shigemoto, R. (2002). Distinct localization of GABA(B) receptors relative to synaptic sites in the rat cerebellum and ventrobasal thalamus. Eur J Neurosci 15, 291-307.

Larkum, M.E., Nevian, T., Sandler, M., Polsky, A., and Schiller, J. (2009). Synaptic integration in tuft dendrites of layer 5 pyramidal neurons: a new unifying principle. Science $325,756-$ 760.

861

Ly, R., Bouvier, G., Szapiro, G., Prosser, H.M., Randall, A.D., Kano, M., Sakimura, K., Isope, P., Barbour, B., and Feltz, A. (2016). Contribution of postsynaptic T-type calcium channels to parallel fibre-Purkinje cell synaptic responses. J Physiol 594, 915-936.

865

866

Markram, H., Lübke, J., Frotscher, M., and Sakmann, B. (1997). Regulation of synaptic efficacy by coincidence of postsynaptic APs and EPSPs. Science 275, 213-215.

Marr, D. (1969). A theory of cerebellar cortex. J Physiol 202, 437-470. motor learning? Toward a resolution without a smoking gun. Neuron 20, 359-362. Takagishi, Y., Augustine, G.J., and Kano, M. (2000). Local calcium release in dendritic spines required for long-term synaptic depression. Neuron 28, 233-244.

Najafi, F., Giovannucci, A., Wang, S.S.-H., and Medina, J.F. (2014a). Coding of stimulus strength via analog calcium signals in Purkinje cell dendrites of awake mice. Elife 3, e03663.

Najafi, F., Giovannucci, A., Wang, S.S.-H., and Medina, J.F. (2014b). Sensory-driven enhancement of calcium signals in individual Purkinje cell dendrites of awake mice. Cell Rep 6, 792-798.

Najafi, F., and Medina, J.F. (2013). Beyond "all-or-nothing" climbing fibers: graded representation of teaching signals in Purkinje cells. Frontiers in neural circuits 7, 115.

Otsu, Y., Marcaggi, P., Feltz, A., Isope, P., Kollo, M., Nusser, Z., Mathieu, B., Kano, M., Tsujita, channels controls climbing fiber signaling in Purkinje cell dendrites. Neuron 84, 137-151. 
895 Roome, C.J., and Kuhn, B. (2018). Simultaneous dendritic voltage and calcium imaging and somatic recording from Purkinje neurons in awake mice. Nat Commun 9, 3388.

897

898 Roome, C.J., and Kuhn, B. (2019). Voltage imaging with ANNINE dyes and two-photon microscopy of Purkinje dendrites in awake mice. Neurosci Res.

900

Sakurai, M. (1987). Synaptic modification of parallel fibre-Purkinje cell transmission in in vitro guinea-pig cerebellar slices. J Physiol 394, 463-480.

903

904

Sarkisov, D.V., and Wang, S.S.-H. (2008). Order-dependent coincidence detection in cerebellar Purkinje neurons at the inositol trisphosphate receptor. J Neurosci 28, 133-142.

Schonewille, M., Gao, Z., Boele, H.J., Veloz, M.F., Amerika, W.E., Simek, A.A., De Jeu, M.T., 908 Steinberg, J.P., Takamiya, K., Hoebeek, F.E., et al. (2011). Reevaluating the role of LTD in cerebellar motor learning. Neuron 70, 43-50.

910

911 Stuart, G.J., and Häusser, M. (2001). Dendritic coincidence detection of EPSPs and action potentials. Nat Neurosci 4, 63-71.

913

Tempia, F., Alojado, M.E., Strata, P., and Knöpfel, T. (2001). Characterization of the mGluR(1)-mediated electrical and calcium signaling in Purkinje cells of mouse cerebellar slices. J Neurophysiol 86, 1389-1397.

917

Usowicz, M.M., Sugimori, M., Cherksey, B., and Llinás, R. (1992). P-type calcium channels in the somata and dendrites of adult cerebellar Purkinje cells. Neuron 9, 1185-1199.

920

Wang, S.S.-H., Denk, W., and Häusser, M. (2000). Coincidence detection in single dendritic 
Figure supplements

\title{
Dendritic coincidence detection in Purkinje neurons of awake mice
}

\author{
Authors: Christopher J. Roome ${ }^{1^{*}}$, Bernd Kuhn ${ }^{1^{*}}$
}

Affiliation: ${ }^{1}$ Optical Neuroimaging Unit, Okinawa Institute of Science and Technology

Graduate University (OIST), 1919-1 Tancha, Onna-son, Okinawa, 904-0495, Japan.

Figure 1 - figure supplement 1. No difference in subthreshold or suprathreshold voltage signaling or time to eyelid closed between first and last recordings.

Figure 1- figure supplement 2. Suprathreshold dendritic complex spike (DCS) and dendritic spike (DS) detection in Purkinje neuron dendrites of awake mice.

Figure 1 - figure supplement 3. Subthreshold and suprathreshold dendritic voltage signals are time locked to sensory stimuli and not voluntary eye blinks.

Figure 1 - figure supplement 4. Isoflurane induced anesthesia blocks stimulus evoked subthreshold and suprathreshold dendritic voltage signaling.

Figure 1- figure supplement 5. During sensory stimulation the average maximum change in subthreshold voltage is positive and dendritic calcium signals are enhanced.

Figure 3 - figure supplement 1. $\mathrm{Na}^{+}$channel antagonist, Lidocaine, blocks stimulus evoked subthreshold and suprathreshold dendritic voltage signaling and slows stimulus evoked eye blinks.

Figure 7 - figure supplement 1. mGluR antagonist, AIDA, has no effect on evoked eye blink closure time, stimulus evoked subthreshold voltage signaling, or the probability of suprathreshold dendritic signals. 
bioRxiv preprint doi: https://doi.org/10.1101/2020.06.15.152496; this version posted June 15, 2020. The copyright holder for this preprint (which was not certified by peer review) is the author/funder, who has granted bioRxiv a license to display the preprint in perpetuity. It is made available under aCC-BY 4.0 International license.
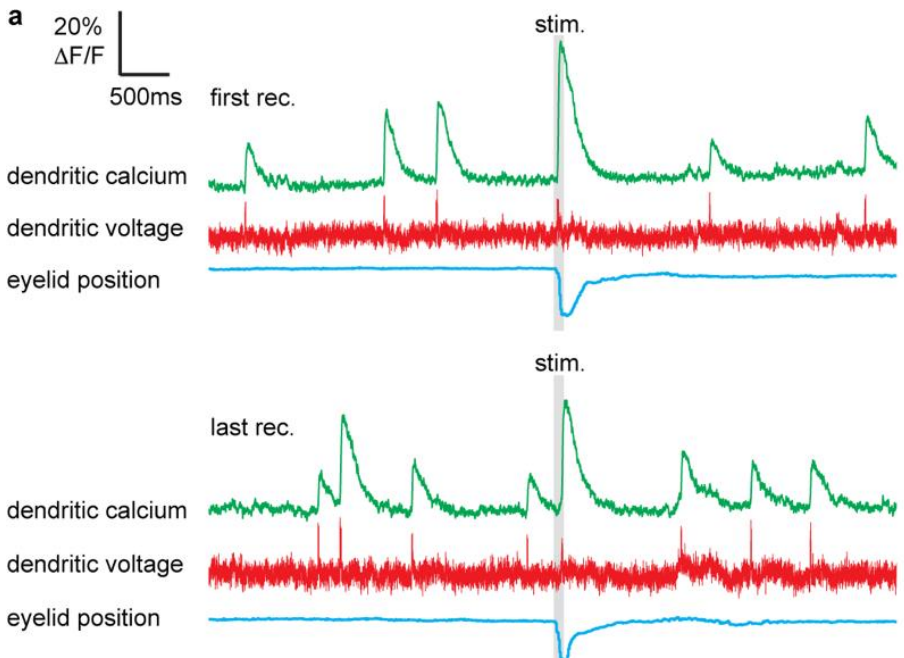
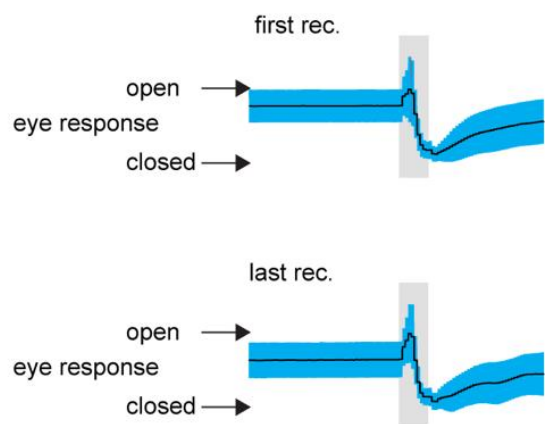

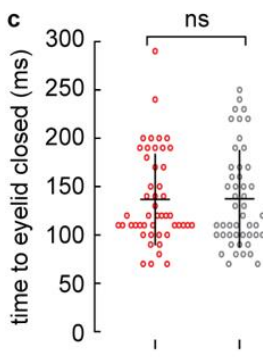

d
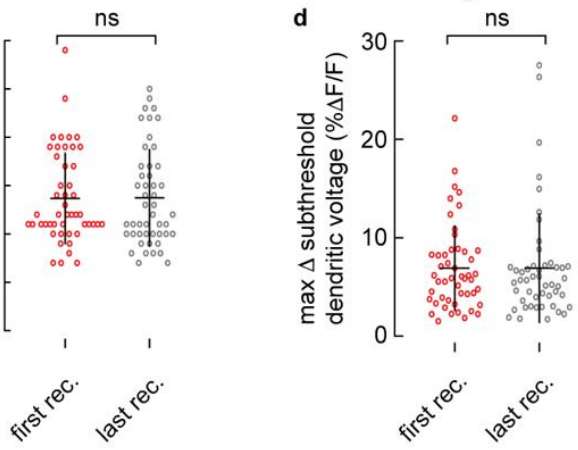

e pre-stim.
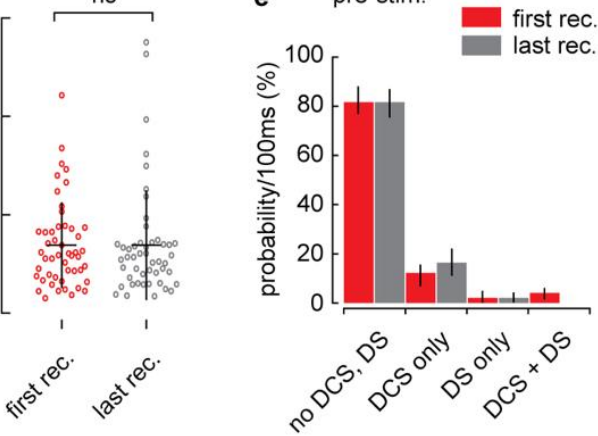

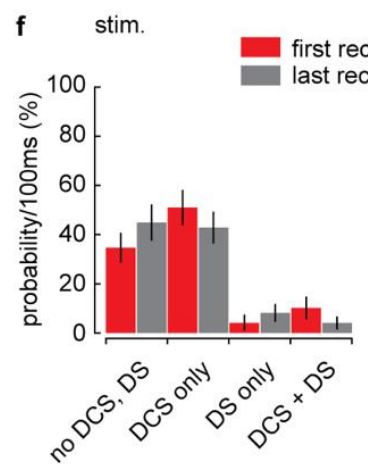

Figure 1 - figure supplement 1. No difference in subthreshold or suprathreshold voltage signaling or time to eyelid closed between first and last recordings.

(a) Single trial recordings of simultaneous dendritic voltage (red traces) and calcium (green traces) during sensory stimulation (stim.). Suprathreshold signals are clearly visible in both voltage and calcium traces. Blue traces show average intensity of ROI used to record eyelid position (eyeblink responses). Grey bars show full duration of air puff stimulus. Top example shows voltage and calcium during first recording (rec.) and bottom example shows last $\left(10^{\text {th }}\right)$ recording from the same PN. (b) Mean eye responses from first (top; $n=49$ ) and last (bottom; $\mathrm{n}=49$ ) recordings (black trace shows mean; blue trace shows SD). (c) Time for eyelid to close after stimulus onset for first (red) and last (grey) recording groups. There was no significant difference in eyelid closure time between first (136 $\pm 47 \mathrm{~ms}$, mean $\pm \mathrm{SD})$, and last $(138 \pm 50 \mathrm{~ms}$, mean $\pm \mathrm{SD})$ groups, $\mathrm{p}=0.97$, Wilcoxon signed rank test, 49 pairs from 49 PNs. (d) Maximum change in subthreshold voltage measured during the stimulus from first and last recordings. Stimulus evoked subthreshold voltage signals from first $6.8 \pm$ $4.3 \% \Delta \mathrm{F} / \mathrm{F}$, mean $\pm \mathrm{SD})$, and last $(6.6 \pm 5.3$ mean $\pm \mathrm{SD})$ recording groups were not significantly different, $\mathrm{p}=$ 0.886, unpaired t-test, 49 pairs from 49 PNs. Probability distributions for suprathreshold DCS and DS signals during pre-stimulus (d) and stimulus (e) time windows, sorted into first and last recording groups (as in (c) and (d)). There were no significant differences in probability distributions between first and last recording groups, during both pre-stimulus and stimulus time windows, Kolmogorov-Smirnov, $\mathrm{p}>0.95,49$ pairs from 49 PNs. Vertical bars in probability distributions show bootstrapped SD. 
bioRxiv preprint doi: https:/doi org/10.1101/2020.06 15.152496: this version posted June 15, 2020. The copyright holder for this preprint (which was not certified by peer review) is the author/funder, who has granted bioRxiv a license to display the preprint in perpetuity. It is made available under aCC-BY 4.0 International license.

a dendritic voltage dendritic calcium extracellular somatic recording

c

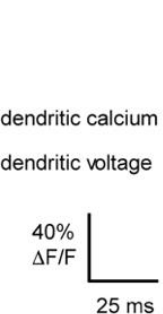

dendritic calcium dendritic voltage

dendritic calcium

extracellular

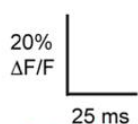

$\boldsymbol{\nabla} \nabla$

$\nabla$

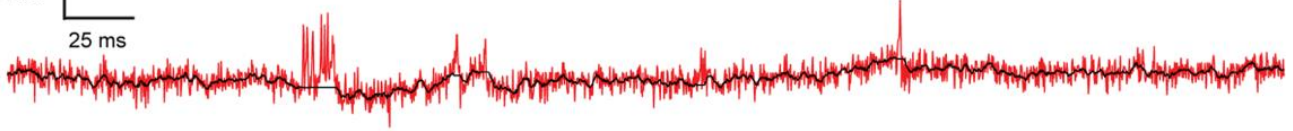

$40 \%$
$\Delta \mathrm{F} / \mathrm{F}$ somatic recording

SS binary (black bars) CS binary (red bars)

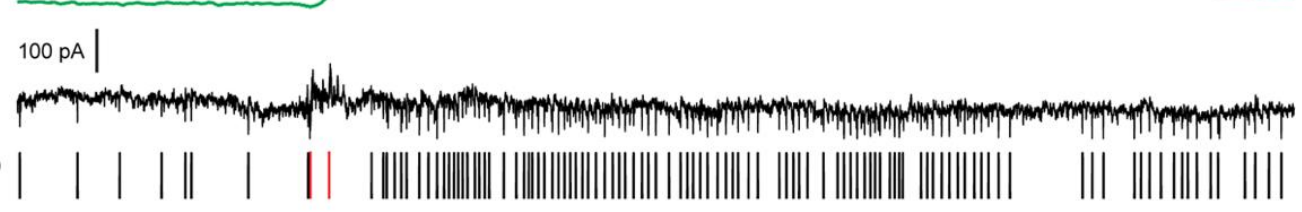

climbing fibre evoked dendritic complex spike (DCS): 32 averages

parallel fibre evoked

dendritic spike

(DS): 25 averages

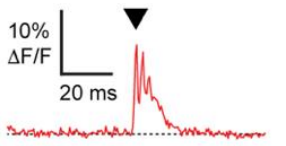

$\nabla$
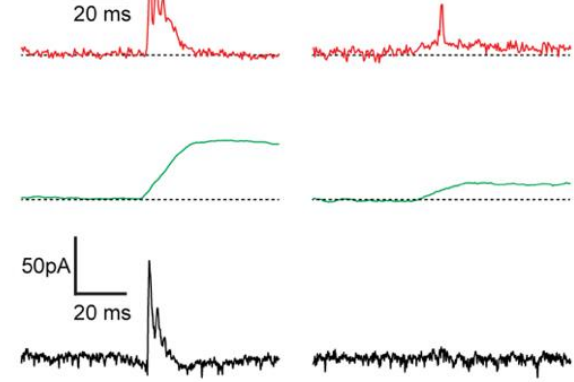

non-evoked

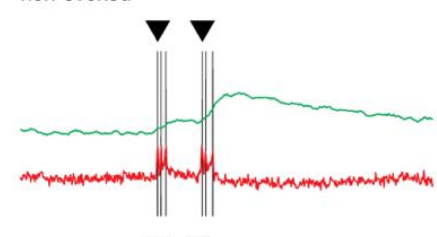

evoked
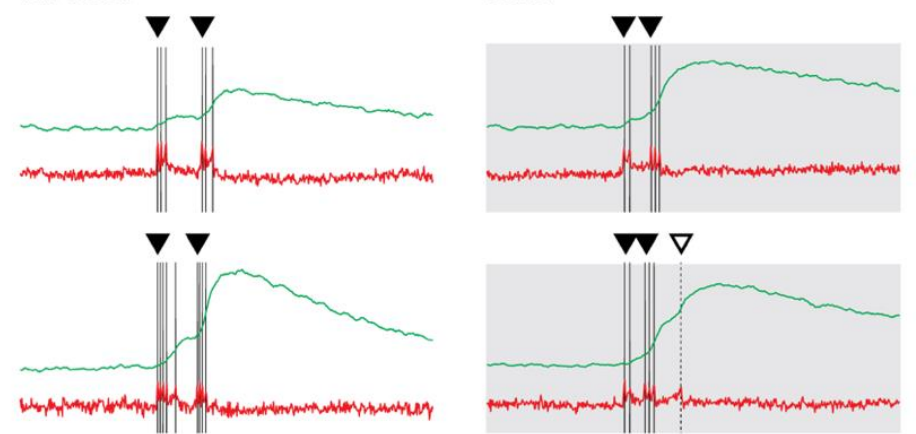

Figure 1 - figure supplement 2. Suprathreshold DCS and DS detection in Purkinje neuron dendrites of awake mice.

(a) Single trial recordings of simultaneous dendritic voltage (red trace, black overlay shows subthreshold voltage, with spikelets removed and $5 \mathrm{~ms}$ boxcar smoothing) and calcium (green trace) and paired extracellular somatic recording (black trace). Binary traces for somatic simple spikes (SS; black bars) and complex spikes (CS; red bars) are shown. (b) averages of 32 DCS signals (left) and 25 DS signals (right), showing dendritic voltage (red), dendritic calcium (green) and extracellular somatic recording (black). Note that DCS signals are characterized by a burst of dendritic spikelets, a large calcium transient, and corresponding complex spike at the soma, while DS signals are characterized by a gradual membrane depolarization, a single spikelet, and small calcium transient in the dendrites, and no corresponding signal at the soma. (c) Single trial recording examples of non-evoked (left) and evoked (right) dendritic voltage spike signals (red) and corresponding dendritic 
bioRxiv preprint doi: https://doi.org/10.1101/2020.06.15.152496; this version posted June 15, 2020. The copyright holder for this preprint (which was not certified by peer review) is the author/funder, who has granted bioRxiv a license to display the preprint in perpetuity. It is made available under aCC-BY 4.0 International license.

62 calcium signals (green) during high frequency DCS and DS activity. Black and dashed bars show detected 63 spikelets during DCS and DS signals respectively. DCS signals are indicated by filled black triangles and DS 64 signals are indicated by open triangles. 
bioRxiv preprint doi: https://doi.org/10.1101/2020.06.15.152496; this version posted June 15, 2020. The copyright holder for this preprint (which was not certified by peer review) is the author/funder, who has granted bioRxiv a license to display the preprint in perpetuity. It is made available under aCC-BY 4.0 International license.
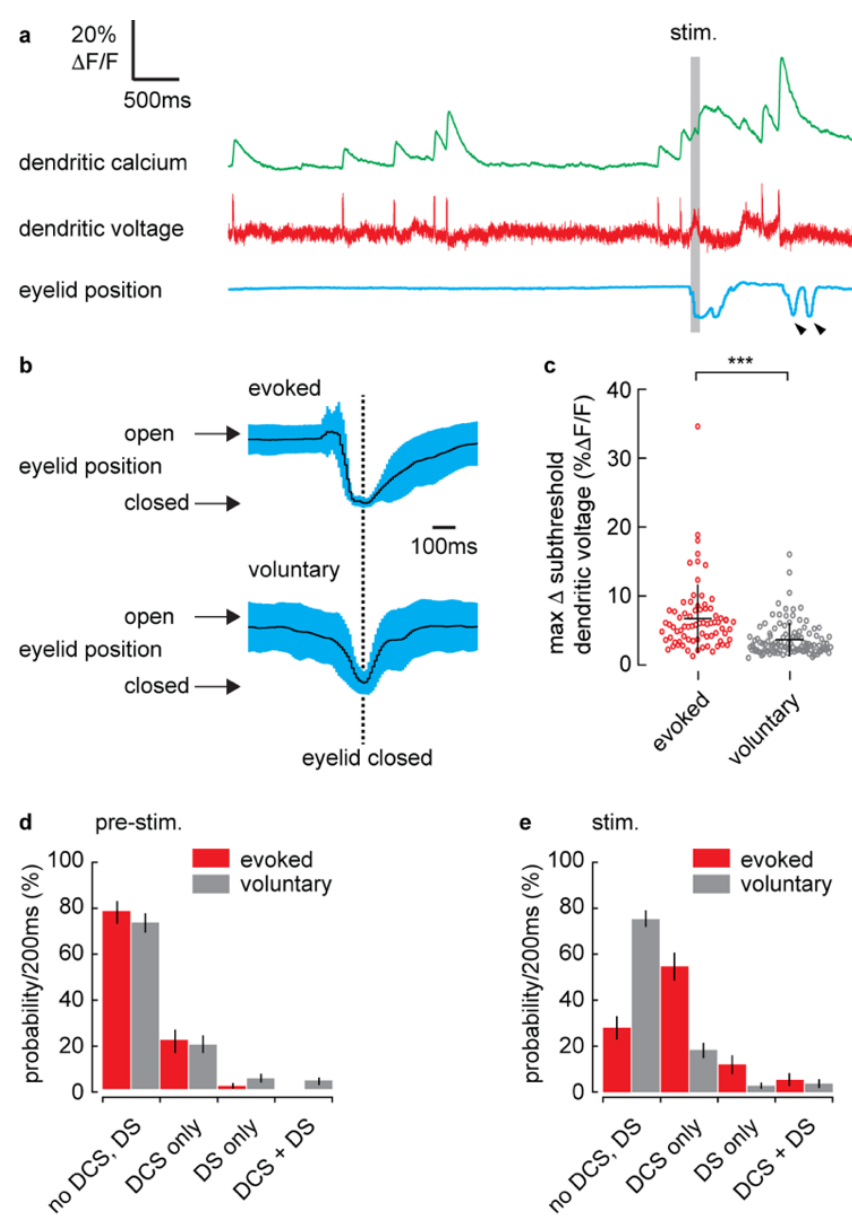

Figure 1 - figure supplement 3. Subthreshold and suprathreshold dendritic voltage signals are time locked to sensory stimuli and not voluntary eye blinks.

(a) Single trial recordings of simultaneous dendritic voltage (red trace) and calcium (green trace) during sensory stimulation (stim.). Suprathreshold signals are clearly visible in both voltage and calcium traces. Blue traces show average intensity of ROI used to record eyelid position (eyeblink responses). Grey bar shows full duration of air puff stimulus. Small black arrows indicate 'voluntary' eye blinks occurring $>1 \mathrm{~s}$ after stimulus ends. For comparison only the recordings containing both evoked and voluntary eye blinks were selected, $(n=75,24$ PNs). (b) Mean eye responses from evoked (top) and voluntary (bottom) eye blinks aligned to full eyelid closure (dashed black line) (black trace shows mean; blue trace shows SD). (c) Maximum change in subthreshold voltage in a $200 \mathrm{~ms}$ window preceding full eyelid closure during evoked and voluntary eye blinks. Stimulus evoked subthreshold voltage signals were significantly larger during evoked eyeblinks; control $(6.7 \pm 5.0 \%$ $\Delta \mathrm{F} / \mathrm{F}$, mean $\pm \mathrm{SD}, \mathrm{n}=75)$, compared to voluntary eyeblinks (3.7 $\pm 2.4 \% \Delta \mathrm{F} / \mathrm{F}$, mean $\pm \mathrm{SD}, \mathrm{n}=109)$, unpaired t-test, $\mathrm{p}=1.1 \times 10^{-7}, \mathrm{n}=75,24$ PNs. Probability distributions for suprathreshold DCS and DS signals during a pre-stimulus (d) and stimulus (e) time window, for evoked and voluntary eyeblinks. Pre-stimulus time windows are defined here as a $200 \mathrm{~ms}$ window, beginning $500 \mathrm{~ms}$ before eye closure. Stimulus time windows are defined here as a $200 \mathrm{~ms}$ window immediately preceding eyelid closure. There was no difference between evoked and voluntary eyeblink probability distributions during pre-stimulus time windows (pre-stimulus, $p=0.98$ ). During stimulus time windows the evoked eyeblink probability distribution was shifted towards a higher probability of 
bioRxiv preprint doi: https://doi.org/10.1101/2020.06.15.152496; this version posted June 15, 2020. The copyright holder for this preprint (which was not certified by peer review) is the author/funder, who has granted bioRxiv a license to display the preprint in perpetuity. It is made available under aCC-BY 4.0 International license.

86 suprathreshold signals compared to voluntary eyeblinks (stimulus, $\mathrm{p}=2.17 \times 10^{-9}$ ). Kolmogorov-Smirnov, $\mathrm{n}=$ 8775,24 PNs. Vertical bars in probability distributions show bootstrapped SD. $* * *$ indicate $\mathrm{p}<0.001$. 
bioRxiv preprint doi: https://doi.org/10.1101/2020.06.15.152496; this version posted June 15, 2020. The copyright holder for this preprint (which was not certified by peer review) is the author/funder, who has granted bioRxiv a license to display the preprint in perpetuity. It is made available under aCC-BY 4.0 International license.
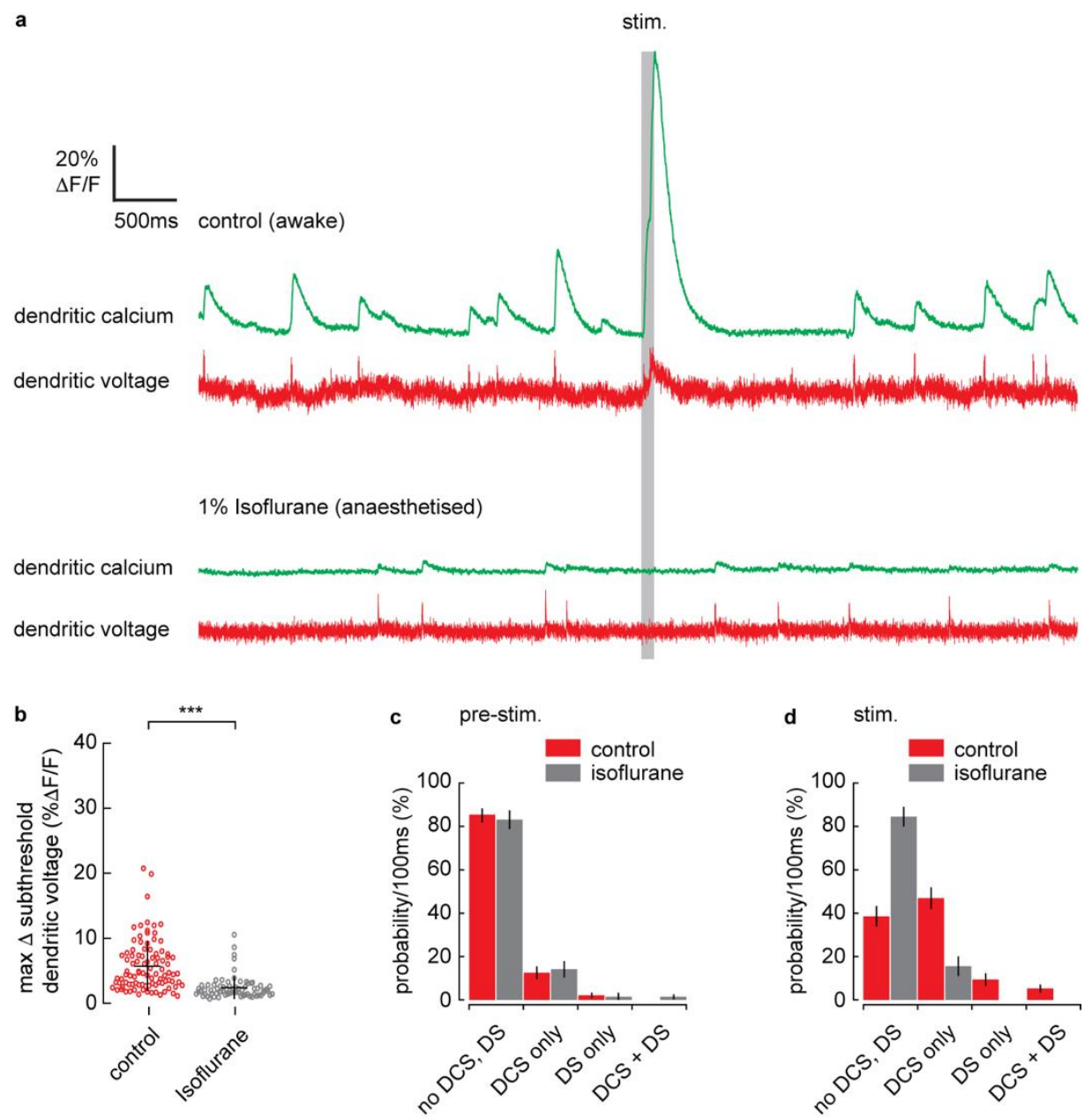

Figure 1 - figure supplement 4. Isoflurane induced anesthesia blocks stimulus evoked subthreshold and suprathreshold dendritic voltage signaling.

(a) Single trial recordings of simultaneous dendritic voltage (red traces) and calcium (green traces) during sensory stimulation (stim.). Suprathreshold signals are clearly visible in both voltage and calcium traces. Grey bars show full duration of air puff stimulus. Top example shows voltage and calcium recordings during control (awake) conditions and bottom example shows recordings during anesthesia (1\% Isoflurane) from the same PN. (b) Maximum change in subthreshold voltage measured within a $200 \mathrm{~ms}$ window after stimulus onset under control (red) and Isoflurane (grey) conditions. Stimulus evoked subthreshold voltage signals were significantly reduced during anesthesia; control $(5.7 \pm 3.9 \% \Delta \mathrm{F} / \mathrm{F}$, mean $\pm \mathrm{SD}, \mathrm{n}=96)$, and Isoflurane $(2.4 \pm 1.7 \% \Delta \mathrm{F} / \mathrm{F}$, mean $\pm S D, n=71$ ), unpaired t-test, $\mathrm{p}=2.4 \times 10^{-10}, \mathrm{n}=167,6$ PNs. Probability distributions for suprathreshold DCS and DS signals during (c) pre-stimulus and (d) stimulus time windows, under control and Isoflurane conditions. Probability distributions during pre-stimulus time windows were unaltered by isoflurane; (prestimulus, $\mathrm{p}=1.0$ ). Probability distributions during stimulus time windows were shifted towards a higher probability of no-signals during isoflurane anesthesia, (stimulus; $\mathrm{p}=3.1 \times 10^{-8}$ ). Unlike in awake conditions, during anesthesia there was no difference between pre-stimulus and stimulus probability distributions $(p=1.0)$. Kolmogorov-Smirnov, $\mathrm{n}=167,6$ PNs. Vertical bars in probability distributions show bootstrapped SD. $* * *$ indicate $\mathrm{p}<0.001$. 

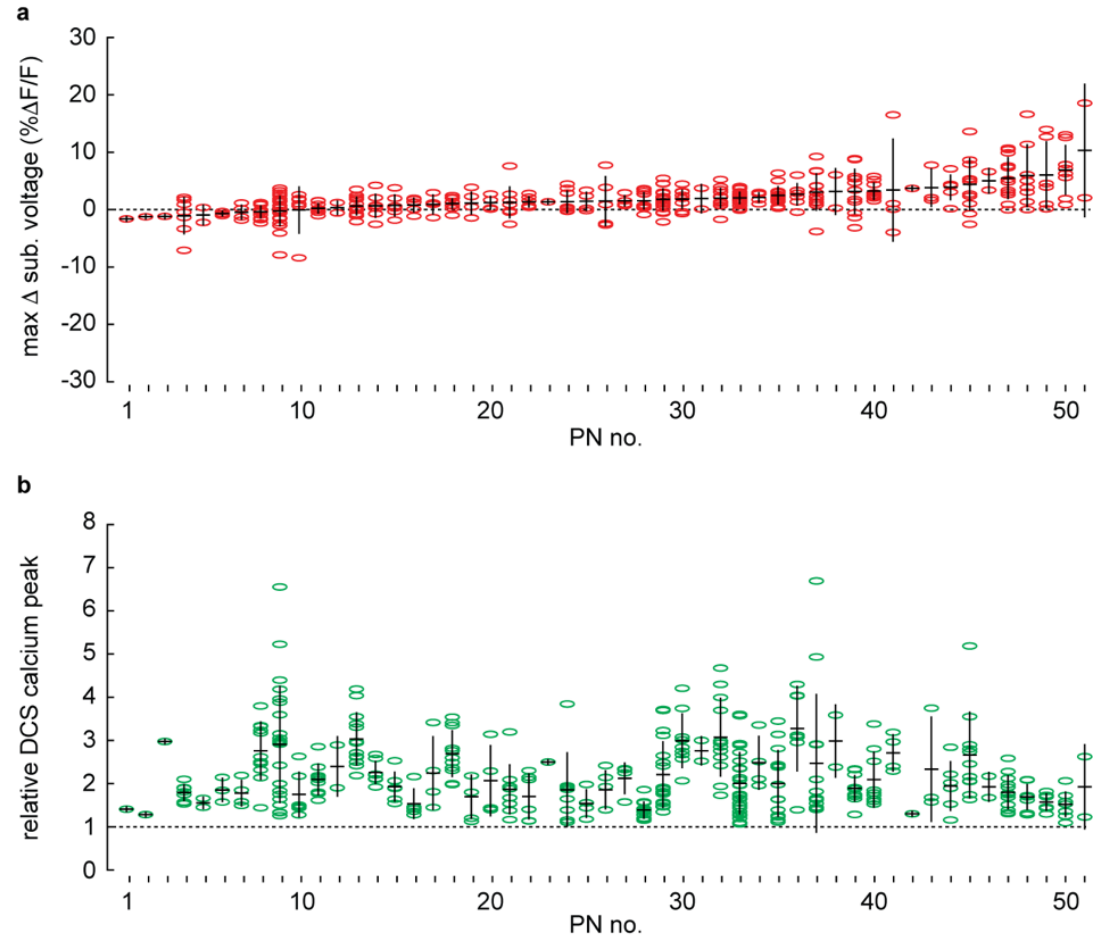

110 Figure 1 - figure supplement 5. During sensory stimulation the average maximum change in subthreshold 111 voltage is positive and dendritic calcium signals are enhanced.

113 (a) Maximum change in subthreshold voltage during sensory stimulation measured from all recordings with 114 evoked DCS signals, $\mathrm{n}=365,51$ PNs (sorted in ascending order based on average for each PN); group average; $1152.0 \pm 2.3 \% \Delta \mathrm{F} / \mathrm{F}$, is significantly above baseline (dashed line), $\mathrm{p}=2.0 \times 10^{-7}$, $\mathrm{t}$-test. (b) Stimulus evoked DCS 116 associated calcium signals, relative to the average non-evoked DCS calcium signal for each PN, $\mathrm{n}=365,51$ 117 PNs, using the same sorting as in (a), group average; $1.4 \pm 0.6$, is significantly above baseline (dashed line), $\mathrm{p}=$ $1181.5 \times 10^{-5}$, t-test. 
bioRxiv preprint doi: https://doi org/10.1101/2020.06 15.152496; this version posted June 15, 2020. The copyright holder for this preprint (which was not certified by peer review) is the author/funder, who has granted bioRxiv a license to display the preprint in perpetuity. It is made available under aCC-BY 4.0 International license.
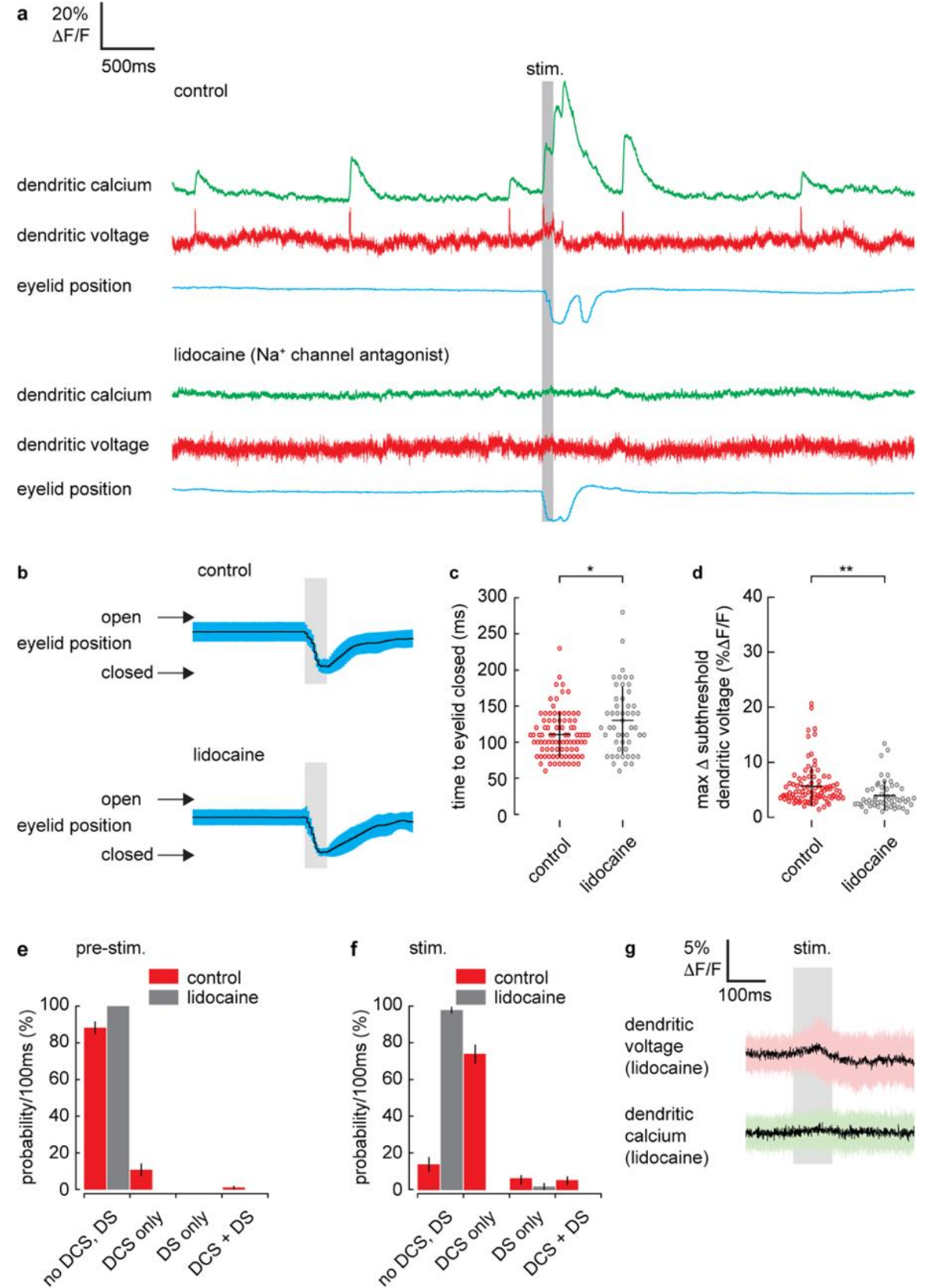

121 Figure 3 - figure supplement $1 . \mathrm{Na}^{+}$channel antagonist, Lidocaine, blocks stimulus evoked subthreshold and suprathreshold dendritic voltage signaling and slows stimulus evoked eye blinks.

124 (a) Single trial recordings of simultaneous dendritic voltage (red traces) and calcium (green traces) during sensory stimulation (stim.). Suprathreshold signals are clearly visible in both voltage and calcium traces. Blue traces show average intensity of ROI used to record eyelid position (eyeblink responses). Grey bars show full duration of air puff stimulus. Top example shows voltage and calcium during control conditions and bottom example shows recordings following Lidocaine application from the same PN. (b) Mean eye responses from control (top, $\mathrm{n}=93$ ) and Lidocaine (bottom, $\mathrm{n}=54$ ) recordings (black trace shows mean; blue trace shows SD). (c) Time for eyelid to close after stimulus onset under control (red) and Lidocaine (grey) conditions. There was a small but significant increase in eyelid closure time following Lidocaine application; control $(111 \pm 31 \mathrm{~ms}$, 
132 mean $\pm \mathrm{SD}, \mathrm{n}=90)$; Lidocaine $(131 \pm 46 \mathrm{~ms}$, mean $\pm \mathrm{SD}, \mathrm{n}=50)$, Kolmogorov-Smirnov, $\mathrm{p}=0.02, \mathrm{n}=140,6$

133 PNs. (d) Maximum change in subthreshold voltage measured within a $200 \mathrm{~ms}$ window after stimulus onset under

134 control and Lidocaine conditions. Stimulus evoked subthreshold voltage signals were significantly reduced

135 following Lidocaine application; control $(5.7 \pm 3.7 \% \Delta \mathrm{F} / \mathrm{F}$, mean $\pm \mathrm{SD}, \mathrm{n}=93)$, and Lidocaine $(3.9 \pm 2.7 \%$

$136 \Delta \mathrm{F} / \mathrm{F}$, mean $\pm \mathrm{SD}, \mathrm{n}=54)$, unpaired t-test, $\mathrm{p}=0.003, \mathrm{n}=147,6$ PNs. Probability distributions for

137 suprathreshold DCS and DS signals during pre-stimulus (e) and stimulus (f) time windows, under control and

138 Lidocaine conditions (as in (c) and (d)). Lidocaine blocks suprathreshold signals during both pre-stimulus and

139 stimulus time windows. There were no suprathreshold signals detected during the pre-stimulus time window

140 following lidocaine application and probability distributions were shifted towards a higher probability of no-

141 signal following Lidocaine application during the stimulus time window, Kolmogorov-Smirnov, $\mathrm{p}=1.8 \times 10^{-22}, \mathrm{n}$

$142=147,6$ PNs. Vertical bars in probability distributions show bootstrapped SD. $*$ and $* *$ indicate $\mathrm{p}<0.05$ and $\mathrm{p}$

$143<0.01$ respectively. (g) Averages of subthreshold voltage (red) and calcium (green) dendritic signaling during

144 sensory stimulation, following Lidocaine application, black line shows mean, colored trace shows SD. Calcium

145 at stimulation offset was not significantly different from baseline, t-test, $\mathrm{p}=0.2, \mathrm{n}=51,6$ PNs. 
bioRxiv preprint doi: https://doi.org/10.1101/2020.06.15.152496; this version posted June 15, 2020. The copyright holder for this preprint (which was not certified by peer review) is the author/funder, who has granted bioRxiv a license to display the preprint in perpetuity. It is made available under aCC-BY 4.0 International license.
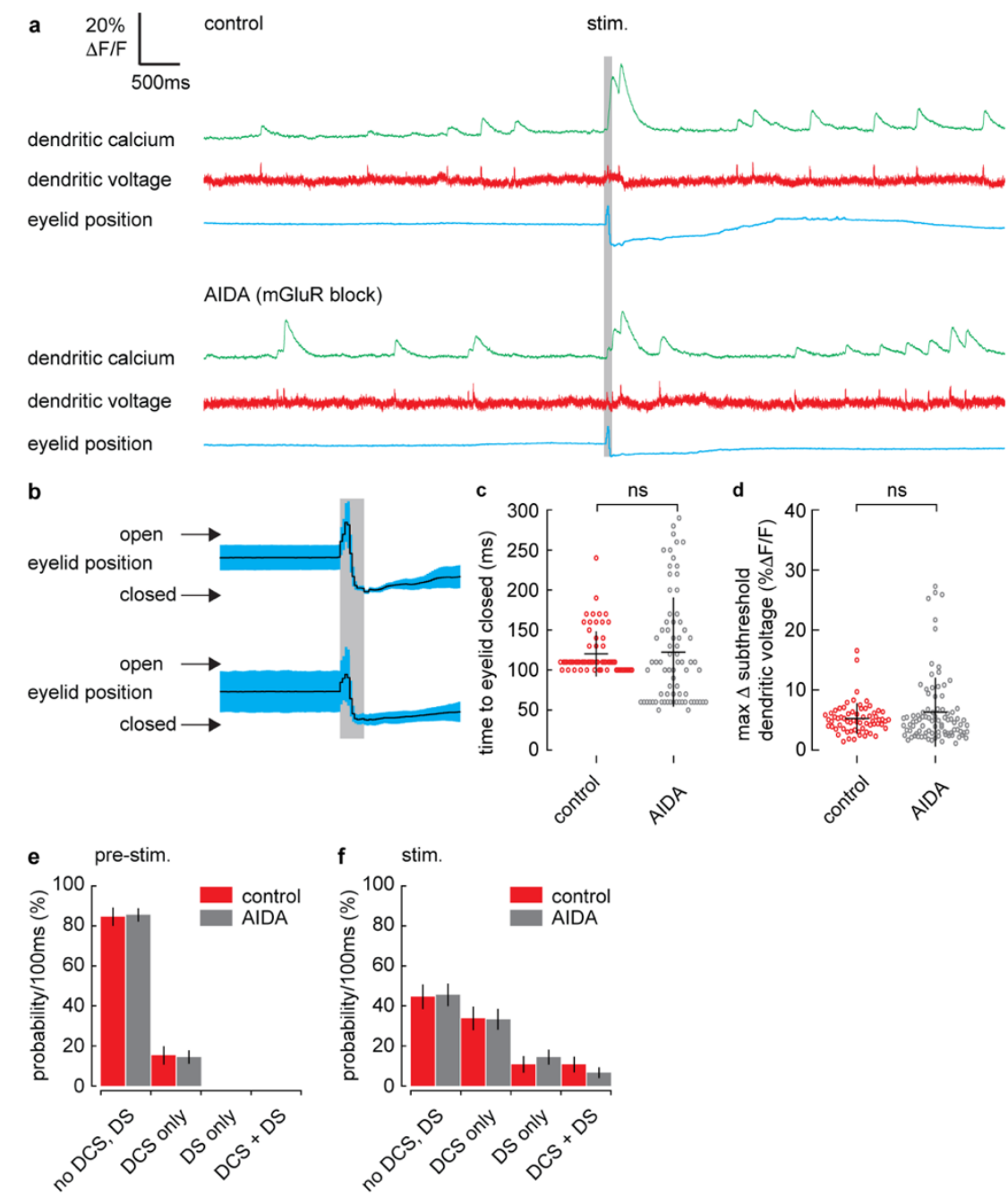

148 Figure 7 - figure supplement 1. mGluR antagonist, AIDA, has no effect of evoked eye blink closure time, stimulus evoked subthreshold voltage signaling or the probability of suprathreshold dendritic signals.

151 (a) Single trial recordings of simultaneous dendritic voltage (red traces) and calcium (green traces) during sensory stimulation (stim.). Suprathreshold signals are clearly visible in both voltage and calcium traces. Blue traces show average intensity of ROI used to record eyelid position (eyeblink responses). Grey bars show full duration of air puff stimulus. Top example shows voltage and calcium during control conditions and bottom example shows recordings following AIDA application from the same PN. (b) Mean eye responses from control (top) and Lidocaine (bottom) recordings (black trace shows mean; blue trace shows SD). (c) Time for eyelid to close after stimulus onset under control (red) and AIDA (grey) conditions. There was no significant difference in eyelid closure time following AIDA application; control (120 $\pm 28 \mathrm{~ms}$, mean $\pm \mathrm{SD}, \mathrm{n}=64)$; AIDA (122 \pm 68 ms, mean \pm SD, $\mathrm{n}=74$ ), Kolmogorov-Smirnov, $\mathrm{p}=0.29, \mathrm{n}=138,6$ PNs. (d) Maximum change in subthreshold voltage measured within a 200ms window after stimulus onset under control and AIDA conditions. Stimulus evoked subthreshold voltage signals did not change following AIDA application; control $(5.3 \pm 2.6$ mean \pm SD, $\mathrm{n}=65)$, and AIDA $(6.3 \pm 5.8$, mean $\pm \mathrm{SD}, \mathrm{n}=90)$, unpaired $\mathrm{t}$-test, $\mathrm{p}=0.17, \mathrm{n}=155,6$ PNs. Probability

163 distributions for suprathreshold DCS and DS signals during pre-stimulus (e) and stimulus (f) time windows, under control and AIDA conditions (as in (c and d)). AIDA did not alter the probability of suprathreshold 
bioRxiv preprint doi: https://doi.org/10.1101/2020.06.15.152496; this version posted June 15, 2020. The copyright holder for this preprint (which was not certified by peer review) is the author/funder, who has granted bioRxiv a license to display the preprint in perpetuity. It is made available under aCC-BY 4.0 International license.

165 signals during either pre-stimulus or stimulus time windows, (pre-stimulus, $\mathrm{p}=1.0$ ); (stimulus, $\mathrm{p}=1.0$ ),

166 Kolmogorov-Smirnov, $\mathrm{n}=155,6$ PNs. Vertical bars in probability distributions show bootstrapped SD. 